\title{
Visualizing a Possible Future: Map Guidelines for a 3D Detailed Development Plan
}

\author{
Stephanie Judge ${ }^{1}$ (D) $\cdot$ Lars Harrie $^{1}$ (D)
}

(C) The Author(s) 2020

\begin{abstract}
Detailed development plans (DDPs) legally define what can be built on a specific property. A proper visualization of these plans is important to facilitate public participation in the urban planning process. In most countries, visualizations of DDPs are still in the form of static 2D maps, but there is a movement towards 3D interactive maps. This movement could potentially benefit public participation by improving communication of the plan proposal, but it also raises issues concerning the cartographic design. A challenge is that a DDP visualization does not convey what will be built in an area, but rather what could be built within the legal frame of the DDP. This implies that the uncertainty in the cartographic design needs to be addressed. In this study, we develop (based on literature review) and implement preliminary guidelines of a 3D DDP visualization, including interactivity possibilities to explicitly address the issue of uncertainty in DDP visualization. The preliminary guidelines are evaluated by semi-structured interviews with urban planning professionals, and based on the outcome of these interviews, the guidelines are updated. The movement toward 3D DDP visualizations was stressed by the participants as important for improving the public understanding and participation in the urban planning process, when the appropriate cartography and functionality is applied.
\end{abstract}

Keywords Geovisualization · 3D geospatial data · Cartographic design · Detail development plan · Urban planning $\cdot$ Public participation

\section{Introduction}

The planning process is a key for supporting sustainable growth of the urban environment. Within the planning process, geographic visualization (geovisualization) plays a pivotal role. This visualization is important in all phases of the planning process, from early sketches through to the final construction. One part in this process is the visualization of the detailed development plans (DDPs), e.g., the legal document that specifies the property criteria for the new buildings/ infrastructure. In most countries, the visualization of the DDP is still based on 2D maps with a cartographic design that emphasizes the presentation of the property criteria of the plan and simplifies the background map and surrounding area (Fig. 1, left). Examples of property criteria are spatial

Lars Harrie

lars.harrie@nateko.lu.se

1 Physical Geography and Ecosystem Science, Lund University, Sölvegatan 12, SE-223 62 Lund, Sweden limitations of where buildings can be built, maximum building height in various regions, the minimum and maximum exploitation grade (the total building footprint area divided by total plan area), and maximum/minimum size of single buildings. The cartographic emphasis on the property criteria is natural since the DDP is foremost a legal document that is mainly read by specialists.

The DDP is often complemented with visualizations of possible realizations of the plan (Fig. 1, right). These visualizations are below denoted DDP visualizations. The DDP visualizations have no legal status, but they help a reader to understand what could happen in the area. One main criticism towards the DDP visualizations is that many people, decisionmakers as well as the public, think that more realistic-looking visualizations such as these should be interpreted as the decisive outcome (Kibria et al. 2009; Billger et al. 2016). However, from a legal perspective, they are only illustrations of one/several possible realization(s) of the plan, and in reality, the new buildings might look very different from the DDP visualizations.

From a cartographic perspective, the design of DDP visualizations is interesting. It is not only a mapping of the invisible, in the context of mapping the future, but it is also a 

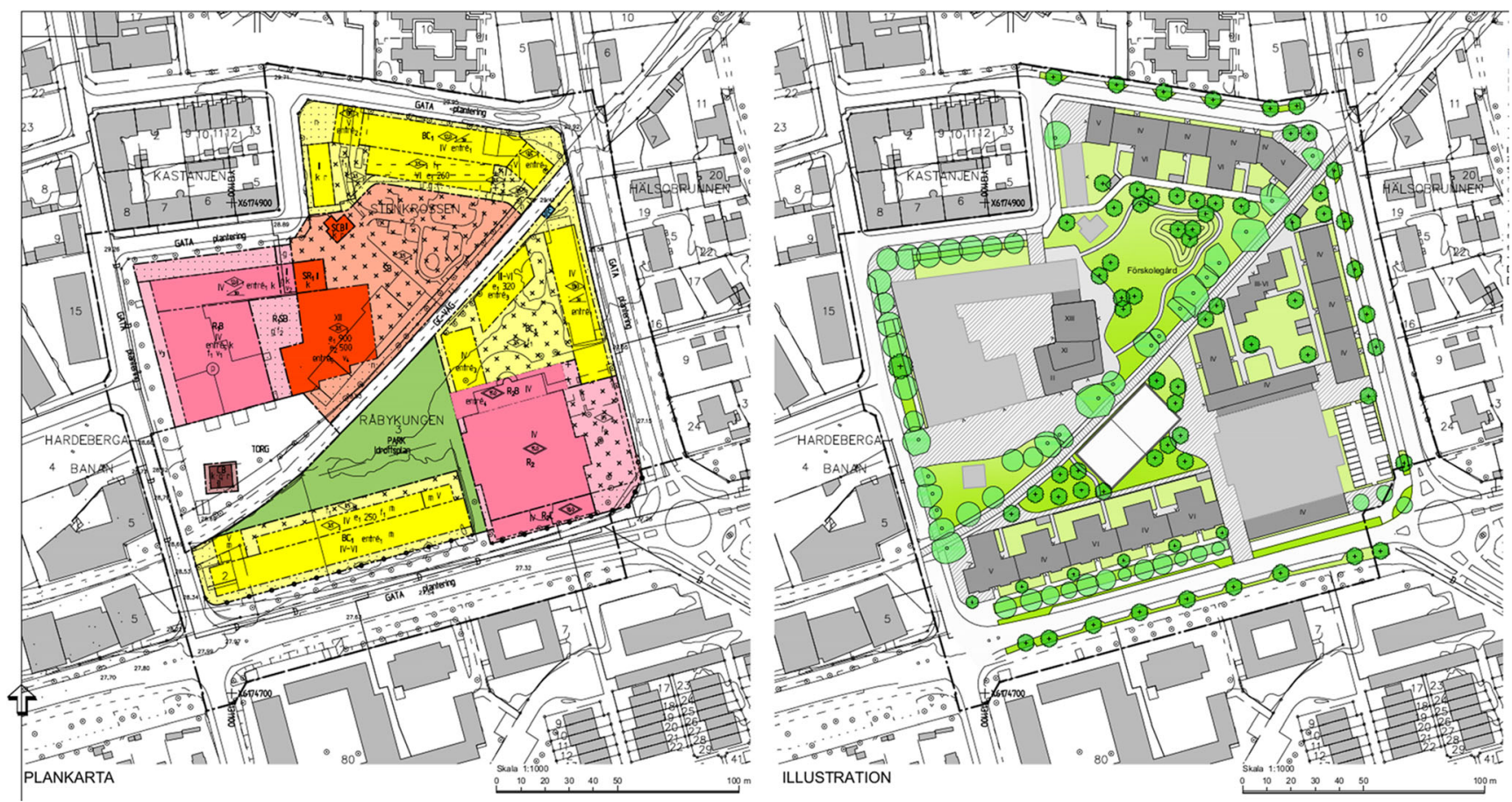

Fig. 1 A detailed development plan (DDP) for an area (Stenkrossen and Råbykungen) in Lund, Sweden (left). A 2D DDP visualization of the DDP (C) Lund Municipality (right)

mapping of something that is uncertain, since the final outcome is unknown at this stage. From a legal perspective, all buildings that are allowed in the DDP are possible in the future. That implies that ideally the DDP visualization should convey some feeling of uncertainty so that the reader understands the actual status of the visualization.

Today there is a movement in many countries towards 3D visualizations in urban design (Wanarat and Nuanwan 2013; Biljecki et al. 2015; Combrinck et al. 2015; Herbert and Chen 2015; Onyimbi et al. 2018). There are both advantages and disadvantages with this movement. One advantage is that, in general, more people are attracted by $3 \mathrm{D}$ visualizations, which implies that their use could enhance the public participation in the planning process; such public participation is often regarded as an important issue to raise sustainability (cf. United Nations 2016b). One disadvantage with 3D visualizations is the likely increase of trust in the DDP visualization; this is a natural effect of most users having more belief in 3D visualizations than in 2D visualizations (Onyimbi et al. 2018). Many DDP visualizations are quite photorealistic (Fig. 2) which further enhances the belief of the visualizations. In all, this stresses the need for good cartographic design for the 3D DDP visualizations.

Another ongoing development of the DDP visualization is from static illustrations and maps towards interactive webbased systems. The latter allows the user to adjust the zoom level and observation points, as well as retrieves information about buildings and other objects (if such information is linked to the objects).
The overall aim of this study is to improve the DDP visualizations to enhance public participation of the urban planning process. There are three specific aims. The first is to provide cartographic guidelines for 3D DDP visualization. The second aim, which is directly linked to the first aim, is to evaluate a methodology that addresses the uncertainty aspects of the realization of a DDP. The third aim is to discuss whether the movement from static 2D to interactive 3D DDP visualizations will improve public participation in the planning process and the role of map guidelines to enhance public participation.

The paper is organized as follows. In the next section, a literature review of $3 \mathrm{D}$ visualizations in general and of visualization plans in particular is provided. The review also contains literature about usage of $3 \mathrm{D}$ visualization to enhance public participation. The subsequent section motivates the cartographic design solutions that are later implemented and evaluated in a case study. This case study is then described in the following section. The paper concludes with discussion, that includes the final guidelines, and conclusions based on the literature and the case study.

\section{Related Studies}

\section{D Visualization in the Planning Process}

An empirical study of geovirtual environments in communicating information in urban plans based in the Netherlands 
Fig. 2 A photorealistic 3D DDP visualization of the DDP in Fig. 1 (C) Lund Municipality

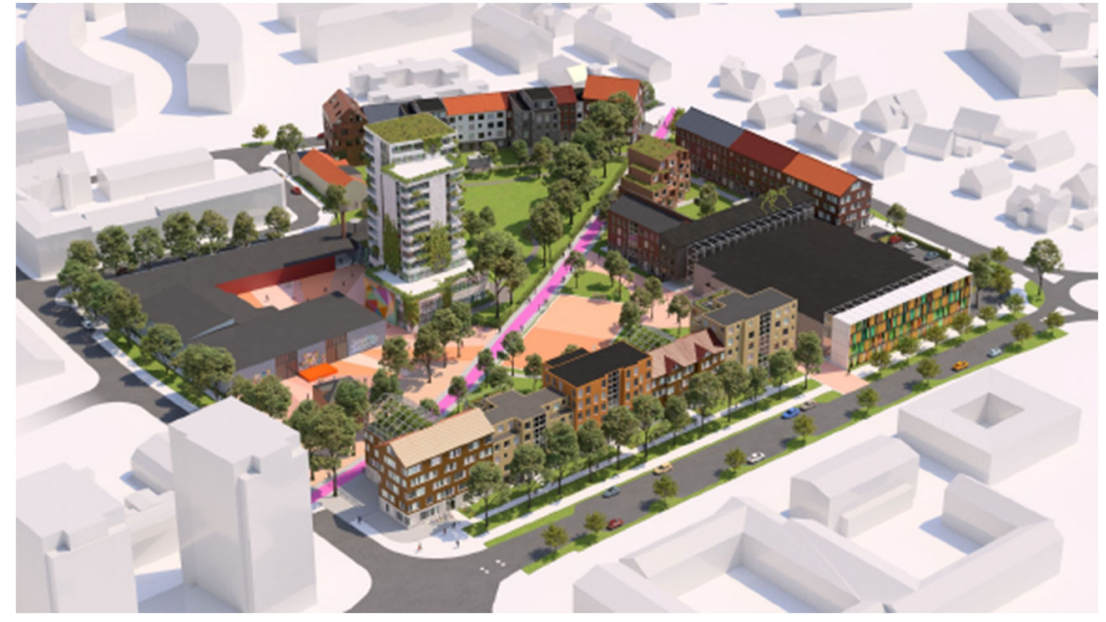

partially investigated the relationship between visual materials and design phase (Kibria et al. 2009). The study found that perception of design increases when moving from $2 \mathrm{D}$ to $3 \mathrm{D}$ higher levels of detail, and that the preference or inclination toward 3D visualizations increased as the building process moved from the abstract (i.e., zoning maps) to the actual (i.e., final building designs) (Kibria et al. 2009). However, their results also indicated that 2D plans and maps retain their relevance in earlier planning stages (Kibria et al. 2009).

A study based on Koh Mudsum, an island in Thailand, explored the improvement in public participation stemming from the use of $3 \mathrm{D}$ visualization in the planning process (Wanarat and Nuanwan 2013). The authors visualized different iterations of proposed building densities so that citizens could more clearly understand the visual impact that the proposals would have on the island, and concluded that the communicative aspect of public participation was facilitated by the use of 3D visualization (Wanarat and Nuanwan 2013, p. 688). A qualitative study based in New Zealand also explored the usefulness of 3D visualizations of buildings based on a detailed plan for the proposal, but with particular focus on shadow visualization (Herbert and Chen 2015). The study found the advantages of $3 \mathrm{D}$ visualization included the added contextual information of visualizing the proposal within the urban landscape, shadow effects, and ability to navigate through the environment (Herbert and Chen 2015).

Today (2020), several Swedish municipalities have begun using DDP visualizations as a communication tool with their citizens. A minor survey conducted by the authors shows at least 14 municipalities in Sweden employing some form of 3D DDP visualizations. In Sweden, DDPs can be broadly grouped into two categories. In the first category, the DDPs are initiated by municipalities since they want exploitation of an area. The property criteria of the DDP are not so specific in this case, to allow for the possibility of many different types of buildings. In contrast, DDPs in the second category are initiated by an external actor, e.g., a commercial developer. In this case, building planning may have already begun, which means that more details are given in the DDP property criteria to allow for that certain development of the area. The category of DDP affects the DDP visualizations, since the first category implies a larger uncertainty about the future buildings. In this study, we are mainly focusing of the visualizations of the first category of DDPs.

A prerequisite for this extended use of 3D DDP visualization is appropriate $3 \mathrm{D}$ city models. Already in 2012, there were more than a thousand models worldwide (Morton et al. 2012), and the number has been growing since. Biljecki et al. (2015) made a review of scientific literature regarding the applications of these $3 \mathrm{D}$ city models and found that visualization in the urban planning process is one common application. In fact, many of the 3D city models are mainly built for visualization purposes. For example, Julin et al. (2018) found that nine out of 19 city models of the larger cities in Finland were related to visually oriented computer graphics culture, and not towards the 3D GIS culture. There is also a trend to import building information models (BIM; Borrmann et al. 2018) into 3D city models. This requires that the BIM models are converted to a $3 \mathrm{D}$ city model standard (most commonly CityGML; see Gröger et al. 2012; Gröger and Plümer 2012). The methodology used for this conversion process has been studied by Stouffs et al. (2018) and Sun et al. (2019), among others. The conversion technique is interesting for the second category of DDPs, since it facilitates that an early stage BIM model could be utilized in the DDP visualization.

\section{Design Principles for 3D Visualizations}

As noted in the previous section, there has been a tremendous technical development of 3D visualizations. However, as Herbert and Chen (2015, p. 22) succinctly stated, "the cartographic theory that may inform these geovisualizations generally trails the technology," indicating that adoption of 3D 
models alone does not improve communication of the plan to its audience. That is, it is important that the cartographic and geovisualization community engages in the cartographic design aspects of the 3D visualizations within the context of its specific use case, e.g., the planning process. In other words, going from a 2D map to a 3D visualization does not imply that we do not need a proper cartographic design: the old truth that maps/visualizations are "best critiqued on how effectively they achieve their communicative purpose" (Muehlenhaus 2013 , p. 412) is still valid. Therefore, it is a positive that several researchers have started to focus on specific design principles which need to be re-thought when moving from 2D to 3D space.

One issue, relevant for the DDP visualization, is photorealistic versus symbolic representation. Intuitively, one could think that photorealistic representation would be preferable because the users are familiar with how things look (see e.g. Collinson 1997). But even though users generally prefer photorealistic representations, it is not certain that they perform better with such representations (Wilkening and Fabrikant 2011). Some studies have shown that domain experts generally prefer symbolic representations; for example, Häberling et al. (2008) interviewed expert users about 3D landscape maps. One issue that was discussed was the Degree of abstraction, where most experts preferred a maplike symbolization (more symbolic than photorealistic). One disadvantage with photorealistic representations is that they provide the users with too much information that obscures the main message. For DDP visualization, it could also be interesting to combine a photorealistic and symbolic representation (for description of this combination, see, e.g., Semmo et al. 2015; Peters et al. 2017). Symbolic representation versus photorealism also affects the users' belief in the visualization which is further discussed in the next section.

If symbolic representation is used for DDP visualization, there is the additional question of which level of detail (LoD) to use (below we use the LoD definition in CityGML; see Gröger et al. 2012 for details). There have been studies of improving visualization of building objects realized by simplifying building data from a higher level of detail (e.g., LoD3) to a lower (e.g., LoD2) (Kada 2007; Fan and Meng 2012; Baig and Abdul-Rahman 2013; Mao and Harrie 2016). The argument for this simplification is both performance (mainly less data needed to be transmitted) and visual quality (remove clutter). One could go one step further and only use 3D buildings (in e.g. LoD2 or 3) for landmarks buildings while the other buildings only are represented using lower built-up area objects (Glander and Döllner 2009). This is an interesting $3 \mathrm{D}$ visualization technique for e.g. navigation, but in our view, it has shortcomings for DDP visualizations since this application also need to visualize non-landmark buildings. Besides the issue of LoD, there is also an issue of which visualization technique (visual variables and their values) to use. Semmo et al. (2012) argue that symbolic representations often lead to monotonic visualization. Therefore, to have an efficient communication, they propose adequate representations on feature levels, e.g., that semantic information (attributes) determines the color of buildings. Neuville et al. (2018) explored visualization parameters that conflict with each other in $3 \mathrm{D}$ space and developed a program that would highlight these conflicts as a user was styling 3D data. Conflict examples from their study included the use of shadows obscuring other objects, transparency leading to a look of superposition, and the difficulty in choosing the "ideal" viewpoint so as not to obscure other data. The pursuance of 3D cartographic principles was conducted in a study by Häberling et al. (2008) who interviewed experts on their preference for various 3D map designs. The authors concluded with 19 design principles concerning degree of abstraction, symbol sizes, view point, lighting aspects, and atmospheric effects; however, an acknowledged study limitation was the focus on static 3D maps.

Advances in 3D visualization have also occurred outside of mapping/geovisualizations, with the gaming industry often leading the way in terms of esthetics and interactivity (Alatalo et al. 2017). The use of employing more game-like $3 \mathrm{D}$ environments in the urban design process has been previously explored (Reika and Weimin 2011; Yan et al. 2011); however, these examples occur in relation to architecture and building design, further along in the planning process than the DDP. Laksono (2019) discussed the challenges of using geodata in game engines, while Mather and Robinson (2016) explored the use of already established gaming environments such as Minecraft to promote citizen engagement. However, research into applying gaming visualization and environments to specific scientific applications, such as protein visualization (Fitz-Walter et al. 2016) and 3D learning environments (Minocha and Reeves 2010), indicate the need for the design to be tailored to the specific application, making it difficult to otherwise generalize 3D design principles.

Ljungblom et al. (2017) discussed the benefits of retaining industry-standard colors from 2D DDP visualizations (Fig. 1, left) to 3D DDP visualizations in Sweden to increase the recognition factor and breed familiarity for working professionals. Herbert and Chen (2015) investigated varying shadow visualizations in a 3D model and found preferences for volumetric shadows over ground-draped shadows, a $40 \%$ transparency setting or the ability to adjust this, and the color blue over gray. A study of visual clutter caused by textual annotations in a 3D model highlighted the need for a proper and intuitive method for the user to parse through annotations, indicating that the reduction of visual clutter was necessary to increase the efficiency of finding relevant data (Camba et al. 2014). This was supported by Ljungblom et al. (2017), who concluded that little to no text in a 3D model was preferred, and that the data should ideally be searchable. Viewing angle 
adjustment and free navigation within the 3D model were noted by Herbert and Chen (2015) as perhaps the most significant advantages of a 3D model.

Despite the increased use of 3D DDP visualizations in Sweden, there is still a lack of national cartographic guidelines of the DDP visualizations, which has resulted in various cartographic solutions for the web-based interactive systems (Fig. 3). Many of the visualization plans lack the possibility to show information about selected objects in the map; instead, more information is provided in sidebars or as links to a PDF-description of the DDP.

\section{Cartographic Studies of Mapping Uncertainty in Planned Reality}

The practice of cartography often involves mapping the invisible. For example, administrative boundaries visualized on maps are not visible in reality, but their meaning and representation on maps is well-understood. Even though these features are invisible, they are well-defined. In contrast, the elements to be mapped in a DDP visualization are both invisible and uncertain. For instance, if the legal DDP dictates the spatial location and size of an allowed building, the visualization of these rules must allow for the possibility of many different outcomes.

There has been extensive research of cartographic design of uncertain information, mainly towards uncertainty linked to data quality (see overview in MacEachren et al. 2005). Even though the uncertainty linked to DDP is somewhat different (uncertainty due to later human decision based on legal constraint), there are interesting results from data uncertainty research that is applicable to this study. Buttenfield and Weibel (1988) created guidelines for mapping uncertainty by matching types of uncertainty (positional accuracy, logical consistency, completeness, etc.), data properties (e.g., measurement scale), and cartographic design methods. Later, there have been a substantial number of studies evaluating different cartographic design methods for uncertainty using intrinsic (changing graphical representation) and extrinsic (change of objects, use of supplementary objects, user interactions, etc.) methods. Example of intrinsic methods is the use of color and transparency to represent uncertainty (Djurcilov et al. 2002; Seipel and Lim 2017). Examples of extrinsic methods are use of the third dimension for uncertainty (e.g., Bevis et al. 2017) and use of visualizing sequences of alternative realizations. The latter is interesting for visualizing uncertainty in outcome of (spatial) modeling (see e.g. Davis and Keller 1997). For mapping uncertainty of 3D building objects, Jones et al. (2013) created and evaluated several methodologies of adding stars to indicate quality. However, there is a challenge of visualizing uncertainty in 3D geovisualization since it needs to include the 3D geospatial data together with the uncertainty data. Using intrinsic methods such as transparency will lead to a color mixing problem that makes it difficult to separate the use of color for thematic information (e.g., building category) with transparency for building information uncertainty. Dübel et al. (2017) argue, based on a study of 3D landscape data, that one should not visualize all information (3D data and uncertainty data) with high accuracy, since this will overload the map reader. Instead, they propose a visualization strategy based on prioritizing the information and visualizing only the most relevant in highest detail.

There has also been research more directly towards handling the uncertainty issue in visualization in the planning process. Billger et al. (2016) raised several challenges with communicating plan proposals to citizens, such as the difficulty in avoiding misrepresentation of reality or the possibility of alternative (and erroneous) interpretations of the data. The authors found that "when high photorealism is used, a sketchy proposal can be understood as a fixed solution" (Billger et al.
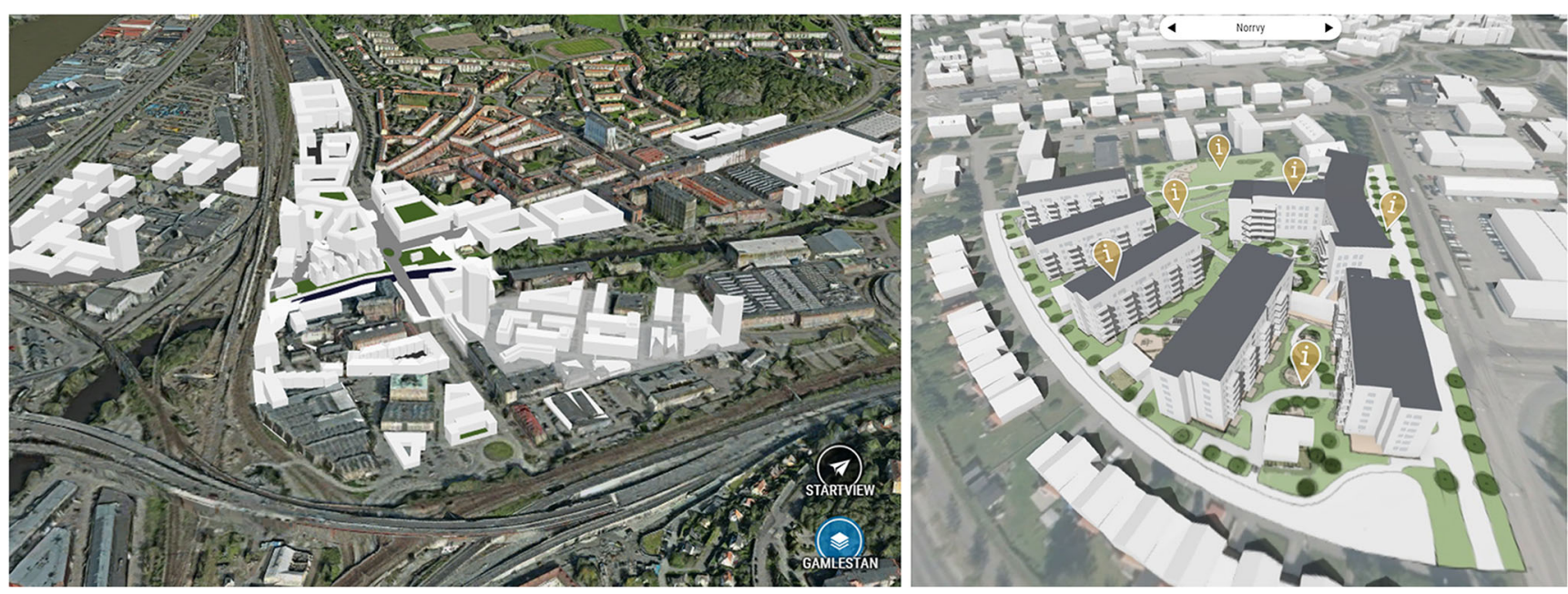

Fig. 3 Various forms of 3D DDP visualizations are being employed by Swedish municipalities, with an example from Gothenburg on the left and Umeå on the right 
2016, p. 15). This is supported by a study completed by Kibria et al. (2009) who found the level of detail (LoD) in the 3D visualization should match the planning stage. The LoD here refers to how they are defined in the CityGML standard, where a higher LoD implies more detail has been employed. In short, in LoD2, a building is represented by box models where the general form of the roofs has been added; in LoD3, the modeling also includes building objects such as doors and windows (see Gröger et al. 2012 for details). Kibria et al. (2009) stated that when the building is visualized in LoD2, the viewers focus on local details of the building design and think that the final design may be altered, while if the same building is viewed in LoD3, the viewers perceive that the building will be fairly similar to the realized building. Indeed, the disconnection between the fact that high realism can impede the core message and the idea that increasingly realistic data representations are preferable is denoted naïve realism in a seminal paper by Smallman and St. John (2005). They argue that displays should highlight task-relevant information, and this process of highlighting inevitably entails paring down reality, a notion supported by Dübel et al. (2017) and Zanola et al. (2009). The latter found that novice users infer significantly more quality in 3D urban data if the data are more photorealistic.

\section{Public Participation}

Onyimbi et al. (2018, p. 1) define public participation as "the process by which an organization [...] consults with interested or affected individuals [...] with the aim of making widely acceptable and sustainable decisions." The significance of public participation in urban planning has been wellestablished in the literature as allowing citizens to feel more engaged and satisfied with their community development, as well as part of a larger functioning democratic process. On the international stage, the Rio Declaration on Environment and Development in 1992 officially stated the importance of public participation at the relevant levels and the need for information to be accessible (United Nations 1992). More recently, the United Nations' Sustainable Development Goals included a specific target for enhancing participatory and sustainable urban planning (Goal 11, target 11.3) (United Nations 2016a), and explicitly named social inclusion as one of the core tenets to achieving sustainable development (United Nations 2016b).

However, public participation methods are not all equal. Arnstein (1969) developed the Ladder of Citizen Participation five decades ago, in which she classified methods of communication on an 8-rung ladder moving from non-participation, through degrees of tokenism before finally arriving at degrees of citizen power (i.e., true participation), in which citizens are empowered and can effect change. On a national level in Sweden, the need for proper citizen dialogue is also recognized by the National Board of Housing, Building and Planning (swe: Boverket). The national board has developed their own set of "participation stairs" based on Arnstein's work and stresses the importance of informing citizens about which level of citizen dialogue is occurring (Boverket 2018). The national board also discusses the importance of citizen participation as part of a true democracy, and the added benefit to the project of the public's intimate knowledge of the municipality (Boverket 2018). McLaren Loring (2007), p.2658) concluded that development projects "with high levels of participatory planning are more likely to be publicly accepted and successful," while Liu et al. (2018, p.1) stated "public participation is critical to the development of urban renewal projects."

For public participation to succeed, the information to be reviewed needs to be understood by the audience. Public participation GIS (PPGIS) is an area of GIS that was first established in the 1990s and was borne out of a desire to better integrate the technological achievements of GIS with the human side of urban planning (Obermeyer 2013). It has been argued that, when communicated poorly, GIS can be an isolating technique, and debate has occurred about the use of GIS as a democratizing or a disenfranchising force (Obermeyer 2013). The potential for unintentional biases led to subsequent PPGIS studies focused on methods to increase public participation in urban planning, or to improve the communication between technical (municipality) and non-technical (citizens) people (Carver et al. 2001).

As early as 2000, Carver et al. (2001) were exploring the usefulness of online GIS systems for communicating with the public and noted the difficulties people had in interpreting highly technical maps. On researching 3D web applications, Alatalo et al. (2017), p.1) stated that 3D visualizations "have proven useful in enabling the participation of the general public in [urban planning projects] since they facilitate efficient communication of plans to non-professionals." A study that evaluated different visualization tools for empowering citizens found that 3D digital modeling had potential for enabling strong levels of "Integration" and "Independence," two of their identified contributions to design empowerment (Senbel and Church 2011). Onyimbi et al. (2018) investigated the use of 3D web-based city models for electronic participation and found that, although the results indicated that the efficiency in which 3D environments could be understood depended on a person's professional background, 3D webbased tools were more effective at communicating information than 2D paper-based presentations.

At the Swedish level, studies as part of the Smart Built Environment program (https://www.smartbuilt.se/inenglish/) also indicate that 3D visualizations could improve citizen dialogue (Almqvist et al. 2016; Ljungblom et al. 2017). The Swedish Mapping Agency (swe: Lantmäteriet) has named the use of $3 \mathrm{D}$ visualization in communication between 
municipalities/authorities and citizens as part of the path toward reaching the goal of digital dialogue in Sweden by 2025 (Lantmäteriet 2019).

The pivotal question in the context of this study is then how the cartographic design should be developed to enhance the relay of information to the public. A critical look at the current 2D DDP visualization (Fig. 1, left) indicates a mass of symbols, text, boundaries, and colors overlaying each other. The reader is required to decipher the many symbols applicable to each spatial boundary and consult the detailed legend for its definition. Without the ability to change the magnification of the static image, information can be deemed simply illegible by the reader. From that perspective, the mapping of the invisible in the DDP context is not served well for the public by the current cartography.

\section{Method}

\section{Research Design}

The aim of this study is to improve DDP visualizations through the use of 3D web-based models. The goal of gaining insight into preferred visualizations for 3D maps is well-suited to qualitative research, which can emphasize a more holistic approach in analysis and allow for more in-depth analysis with fewer participants (Ghauri and Grønhaug 2002). Experts who work in the professions of urban planning and GIS for the municipality were chosen to provide a thorough evaluation of the 3D designs. Wroblewski and Leitner (2009) noted the efficiency gained in using expert interviews to analyze a model, which is beneficial for a study of limited time scope. Interviews are a well-established method for collecting primary data and are preferred over questionnaires for qualitative studies based on the flexibility they allow for the participants' responses (Ghauri and Grønhaug 2002). A semi-structured interview method was chosen in order to strike a balance between allowing for the experts' views and opinions to be expressed while still considering how the research questions would be answered.

The research design is summarized in Fig. 4 and described as follows. Based on the literature review above, preliminary map guidelines were created. Four different designs of a 3D model for the study area were created using different cartographic principles. A qualitative analysis of the maps was undertaken using expert interviews and the map guidelines were revised to reflect the results.

\section{Study Area and Data}

The study is based on a DDP created for a proposed development called Stenkrossen and Råbykungen in Lund, Sweden (Fig. 5). The planning process for the study area began in 2011, and the city continues to move toward the approval stage with the most recent vote at the time of this writing occurring in October 2019 (https://www.lund.se/03-2018). Data provided for the study by Lund Municipality is summarized in Table 1. The DDP used as the basis of this study was the version released during the consultation phase of the planning process (Swe. samrådshandling) on February $1,2018$.

\section{Preliminary Map Design}

The first step in creating the preliminary map guidelines is to provide the cartographic designs, which were based on the reviewed literature above. Although some of the design principles are intended for static maps, they were thought to be applicable in this context. The main design principles used were:

- Avoid known visual conflicts in 3D space - in particular, use transparency, shading, and shadow with caution (Neuville et al. 2018).

- Avoid highly realistic representations (Smallman and St. John 2005; Kibria et al. 2009; Billger et al. 2016).

- Avoid or minimize textual annotations (Camba et al. 2014; Ljungblom et al. 2017).

Four different designs were created which retain these underlying principles. More details can be found online (see Judge 2019).

Design 1 (Fig. 6) was created to test the colors used in the 2D DDP for the study area, i.e., the colors used to display property criteria in Fig. 1 left. The colors draw focus to the study area and refer to the primary land usage in the proposal (i.e., commercial, residential). The background map is visualized with white groundcover and gray streets, while the buildings are visualized as a simple light gray.

Design 2 (Fig. 7) was created to test for a simpler visualization of the study area and more details in the surrounding area, as a contrast to the style of design 1 . The background map includes more colors indicating variable groundcover, while the buildings in the city model are dark gray to give a higher contrast with the background map and differentiate them from the proposal. The proposed building areas are

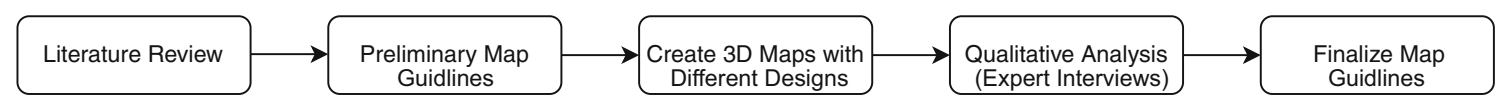

Fig. 4 A summary of the research design for the project 


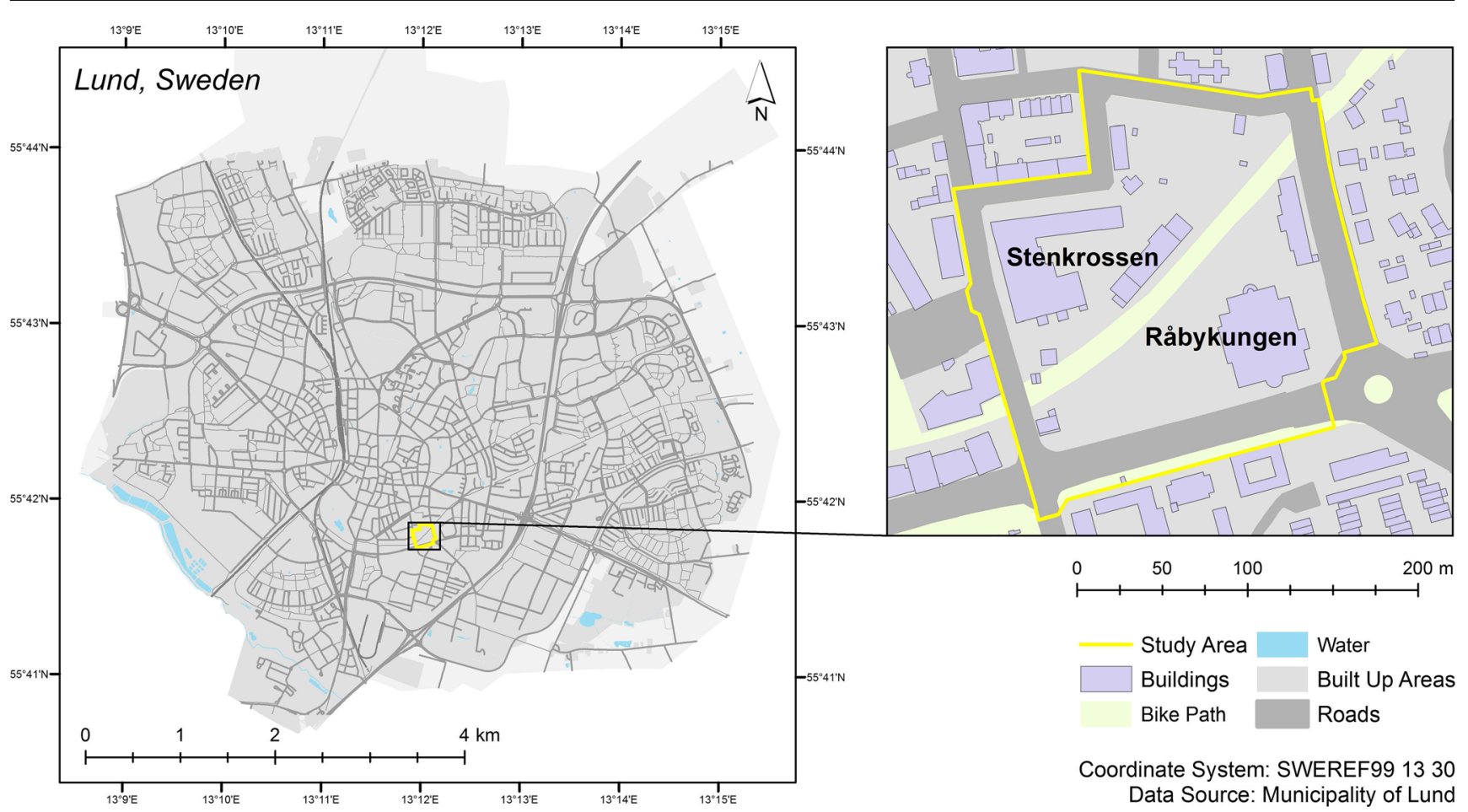

Fig. 5 The location of the study area (Stenkrossen and Råbykungen) within Lund, Sweden

shown in white, with the groundcover of the study area continuing the style of the background map.

Design 3 (Fig. 8) was created to test the same simplified study area but with a more realistic surrounding. The background map uses an orthophoto, and the buildings in the city model are visualized with fictitious facades created with the software CityEngine (there was no existing 3D model of Lund at that detail). The vegetation placement is based on real geodata, but the tree visualization is also generated with the software. The study area is kept in focus by being shown entirely in white, including groundcover.

Design 4 (Fig. 9) was created to test a more abstract style of both the study area and surrounding model. It removes some of the detail from design 3 by using more symbolic styles for the background map (textures for groundcover, like grass, cobblestone, and dark asphalt) and vegetation. The buildings in the city model are shown in white with no further detail, while the study area is kept in focus with dark gray walls and a dark red roof, intended to pull focus and add detail.

\section{Preliminary Method to Map Uncertainty}

The second step in creating the map guidelines is devoted to visualizing the uncertainty of the plan, i.e., to avoid a situation where the 3D DDP visualization is interpreted as a future truth. The selection of the method for representing this uncertainty was based on the following principles:

- Do not to use intrinsic methods such as color and transparency to represent uncertainty (Neuville et al. 2018). This is difficult to interpret in $3 \mathrm{D}$ due to e.g. the color mixing problem.

- Avoid overloading the visualization with too much 3D geodata and uncertainty data in one view (e.g., Dübel et al. 2017).

Based on these statements, an interactive (extrinsic) approach was chosen to stress the uncertainty, an approach based on the user being able to see and compare different scenarios. The hypothesis is as follows: if the
Table 1 Data provided by Lund Municipality for the study

\begin{tabular}{lll}
\hline 2D/3D & File format & Details \\
\hline 2D & DWG (AutoCAD) and PDF & Detailed development plan \\
2D & Shapefiles (ESRI) & Lund base map data (roads, buildings, land use, vegetation) \\
2D & GeoTIFF & Digital elevation model \\
3D & Multipatch (ESRI) & Existing buildings in LoD2 (city model)
\end{tabular}




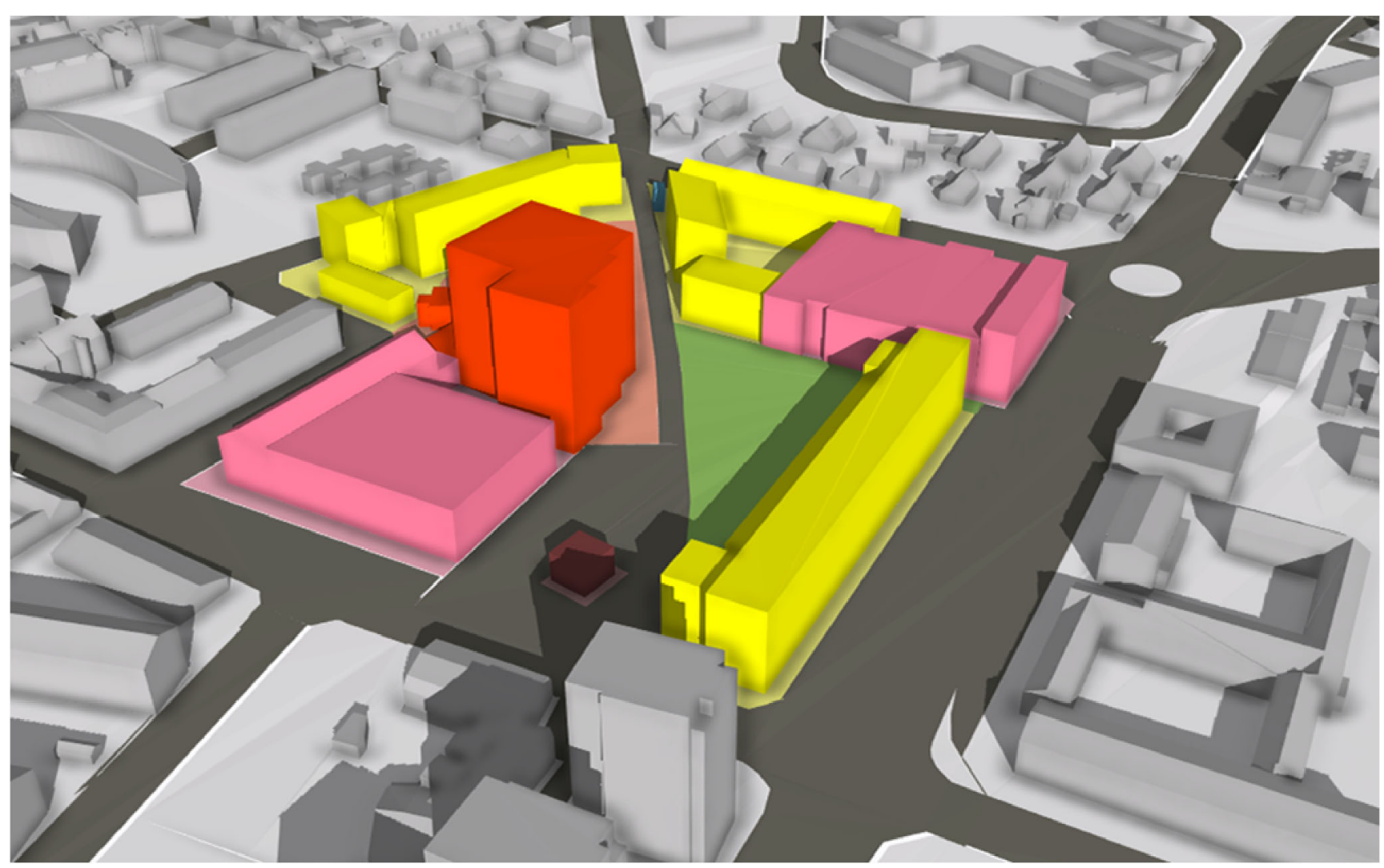

Fig. 6 The study area as visualized in design 1

user could see two different scenarios (which are both possible in terms of the legal constraints of the DDP), it will give them a feeling of the uncertainty in the model. To realize this, one of the scenarios shown could be the outer envelope of each building, which is a maximum legal realization of the building based on easily definable property criteria such as maximum height. The specific comparison mode used in this study is described further in the following subsection, with an example shown in Fig. 10, top.

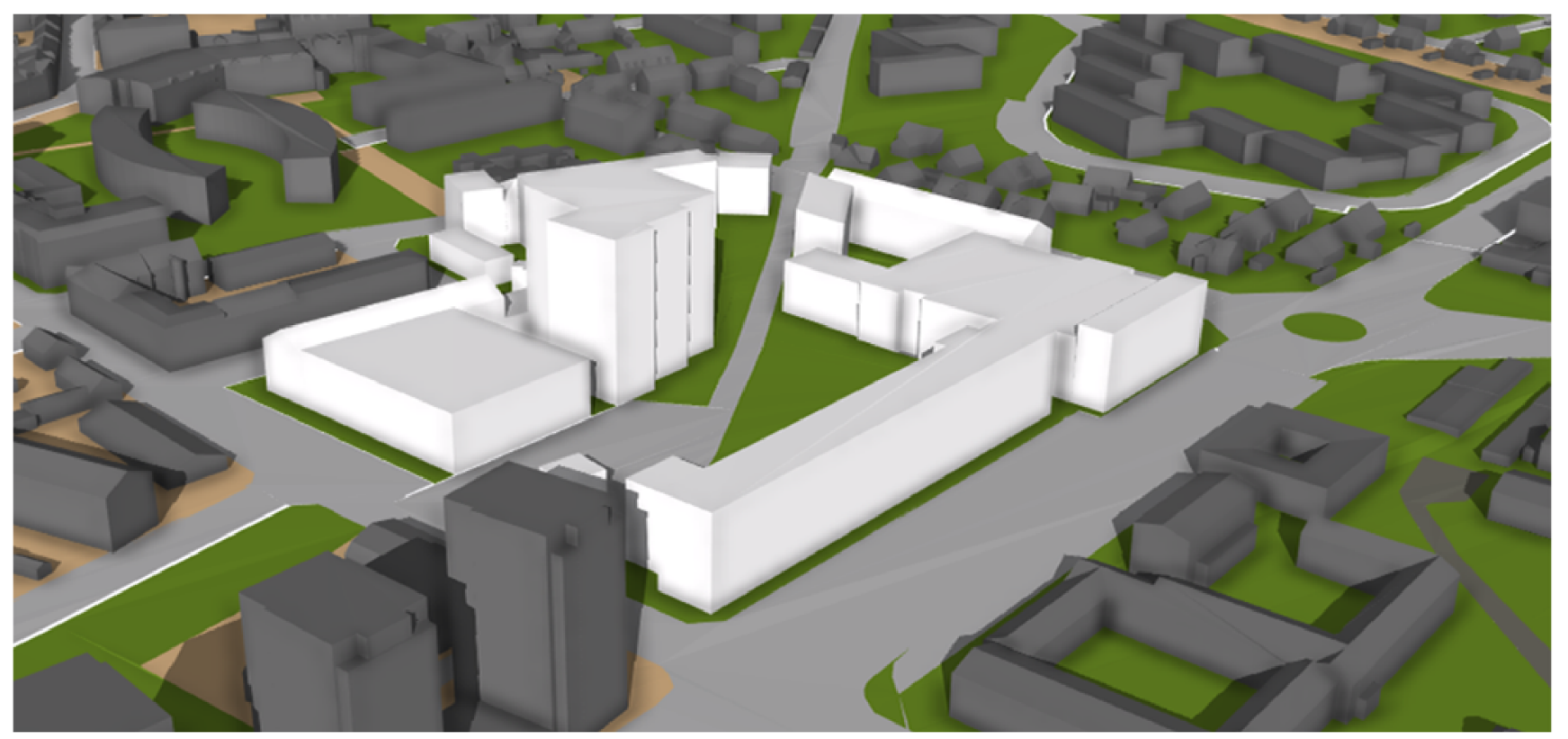

Fig. 7 The study area as visualized in design 2 


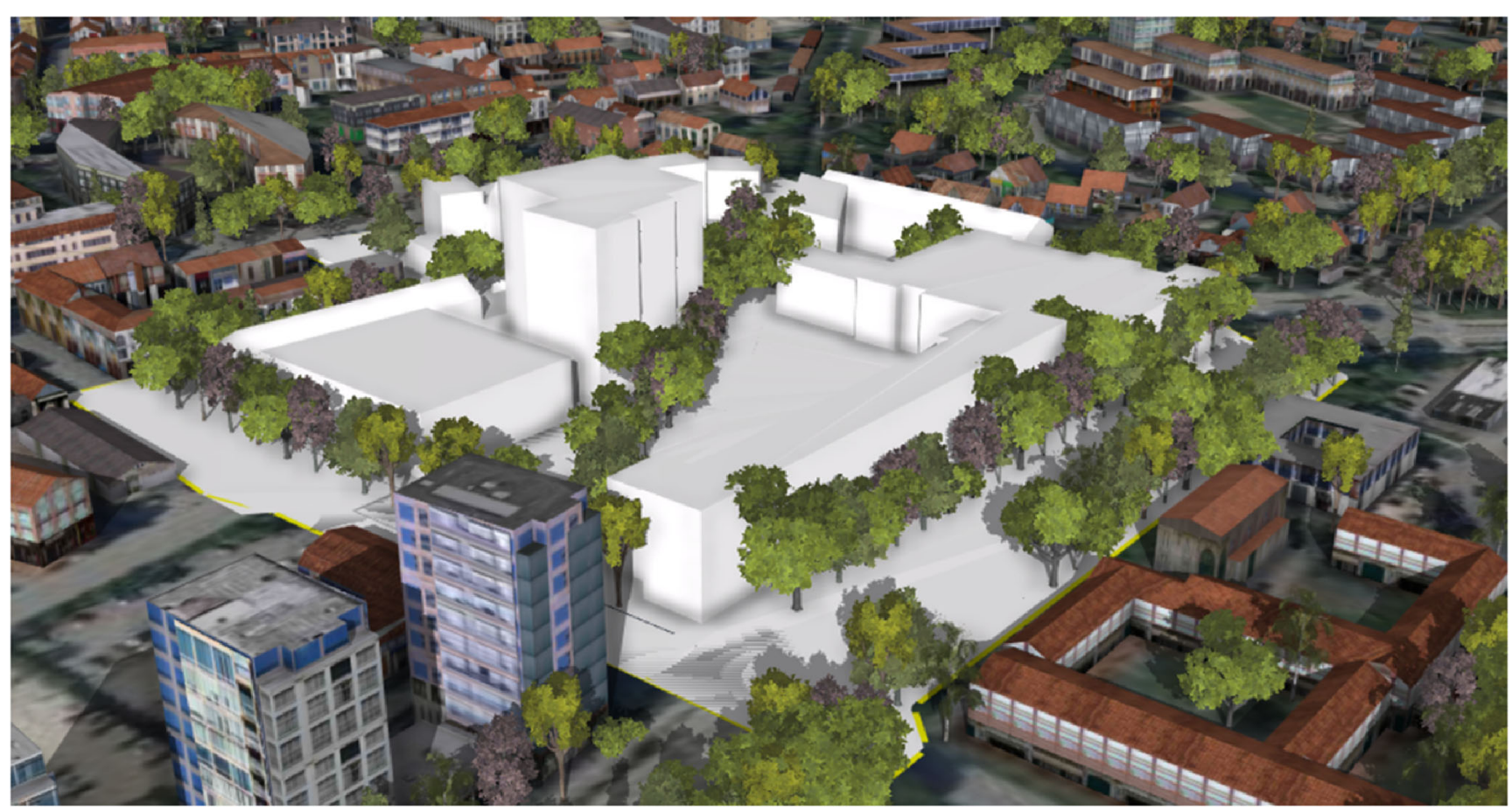

Fig. 8 The study area as visualized in design 3

\section{Practical 3D Map Implementation}

To create an interactive web-based DDP visualization, the following requirements were stated:
- The ability to import the provided data to create the $3 \mathrm{D}$ city model and DDP

- The ability to share the 3D models with participants

- The functionality of comparing two scenarios in the viewer

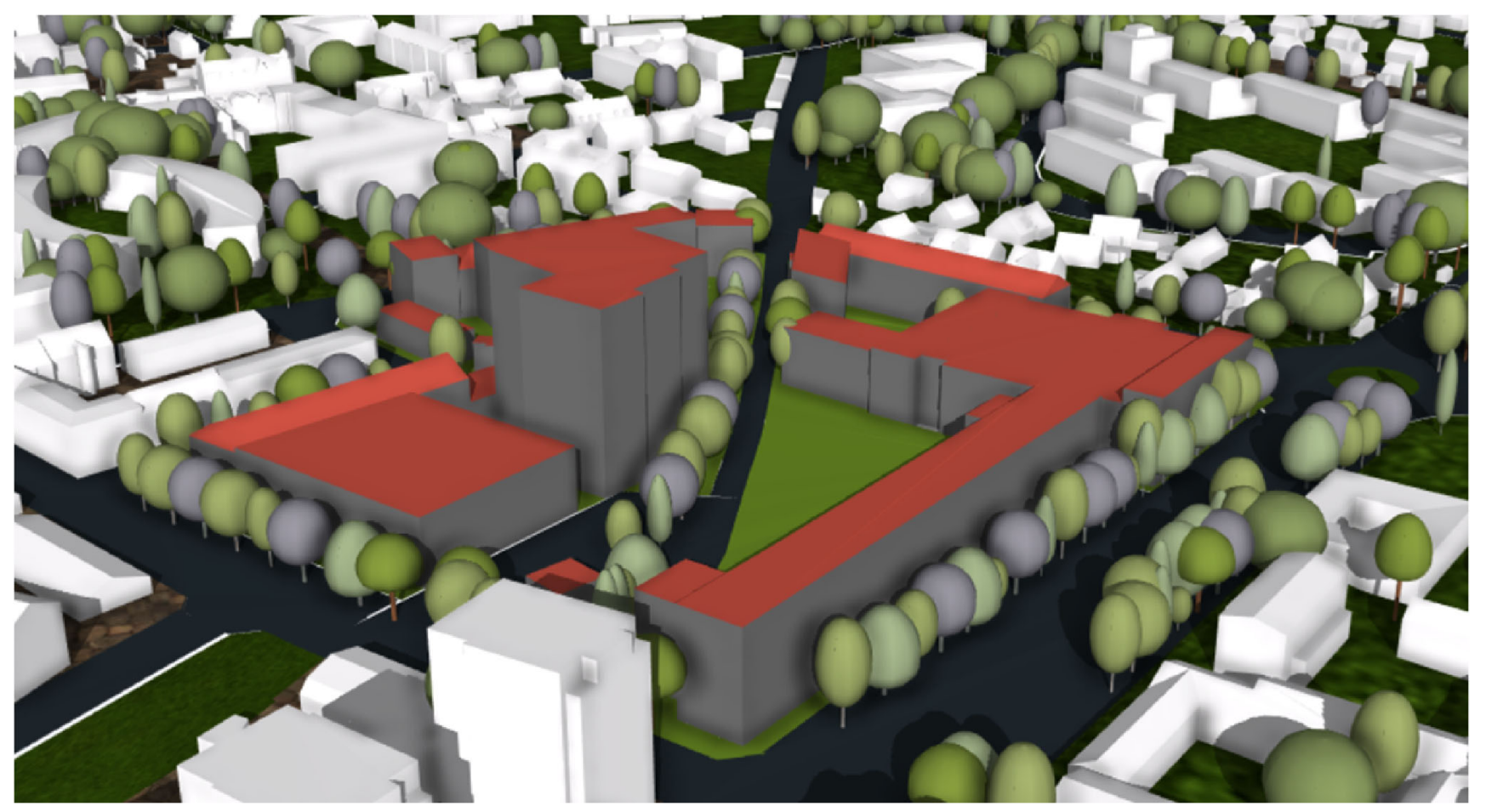

Fig. 9 The study area as visualized in design 4 
Fig. 10 Using design 2 as an example, the comparison mode is shown on the top, while the bottom shows the function of clicking on an object in the DDP and being shown its attributes in an information pane
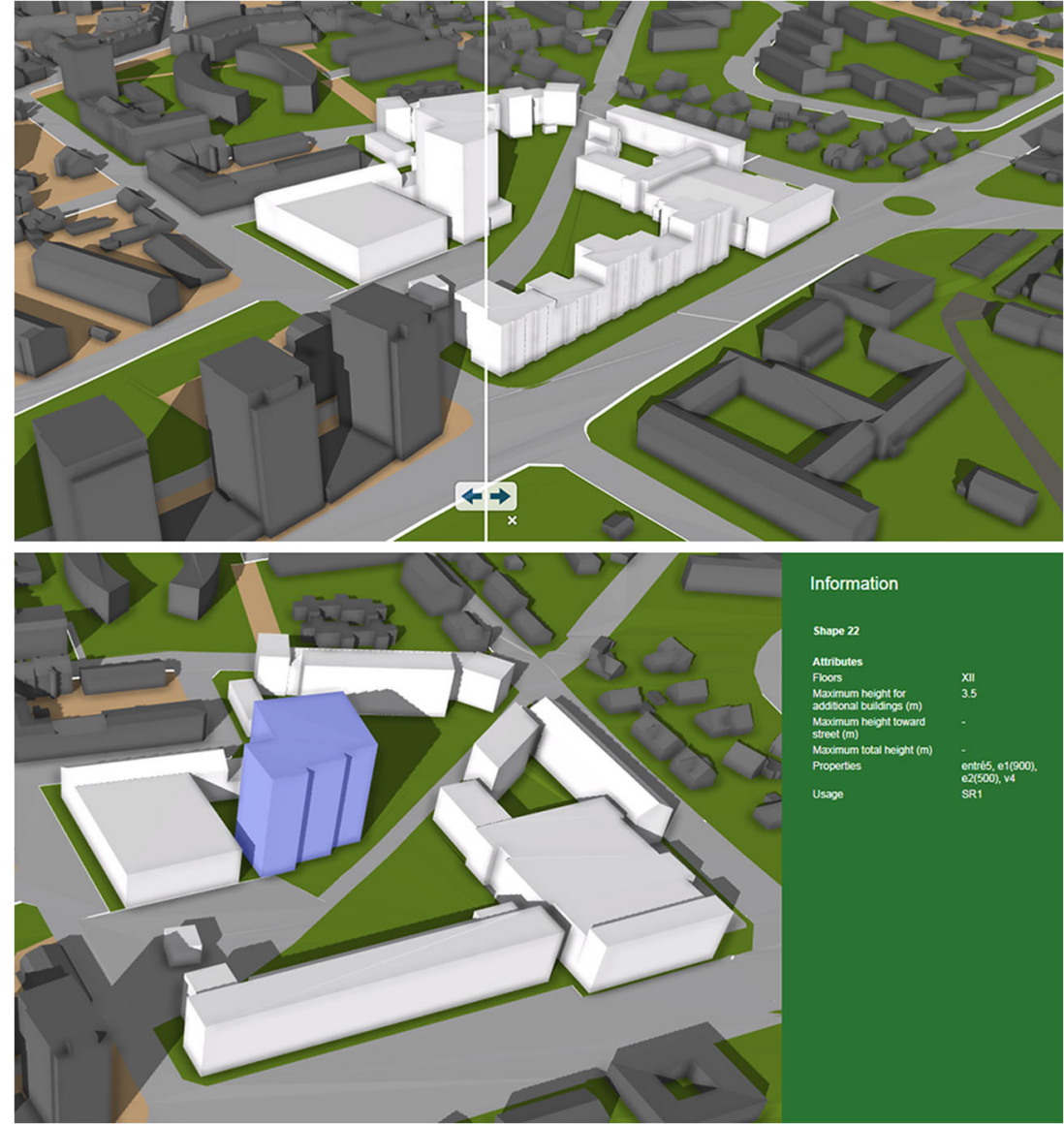

CityEngine is one (of several) software that fulfills these requirements and was therefore chosen for the study. Sharing the 3D model through the web application provided the functionality of allowing viewers to navigate through the model and view it from any angle; alter the sun position to view how shadows would change throughout the days and year; and search attributes related to the DDP or click on an object to view its attributes in an information pane. Foremost, the software provides the possibility of viewing two scenarios simultaneously in comparison mode (Fig. 10).

The base 3D DDP model was created by first translating the provided DWG file into shapefiles using FME 2018.1 (Safe Software). The resulting data was processed in ArcMap 10.5.1 (ESRI) before being imported into a new scene within CityEngine 2018.1 (ESRI). Rule files were created using the CityEngine scripting language Computer Generated Architecture (CGA) shape grammar and were used to generate the $3 \mathrm{D}$ content by extruding polygons to their maximum height based on the information found in the DDP, creating a box model. All polygons within the original DDP boundaries became either objects (3D) or shapes (2D) in the $3 \mathrm{D}$ model, with attributes expressing the information found in the DDP. The 3D model was defined as a type of semantic model, owing to the attribute retention. A 3D city model of Lund does not currently exist, so a surrounding map was created using the provided data in order to place the $3 \mathrm{D}$ DDP within the context of its neighborhood. Due to export size restrictions, only a portion of Lund was visualized in the 3D model.

In CityEngine parlance, three scenarios of the plan area were created for each model design (Fig. 11). The first is the DDP visualized as the outer envelope of the buildings based on the maximum height; the second is an example of one possible realization of the buildings; and the third scenario shows the existing buildings within the study area to provide context to residents. While existing buildings imply a redevelopment is occurring, an alternative scenario (such as another possible realization of the buildings) could be chosen for a new development on an empty lot, or simply visualizing the current study environment even without buildings. For all these scenarios, the existing buildings in the vicinity of the study area were also included. The scenarios were then styled according to the four cartographic designs previously described. Once the 3D DDP visualizations had been completed, they were exported as CityEngine Web Scenes, uploaded to ArcGIS Online, and viewed through CityEngine Web Viewer (see link at Judge 2019). In the comparison mode, the user can select to view two of these scenarios simultaneously. 

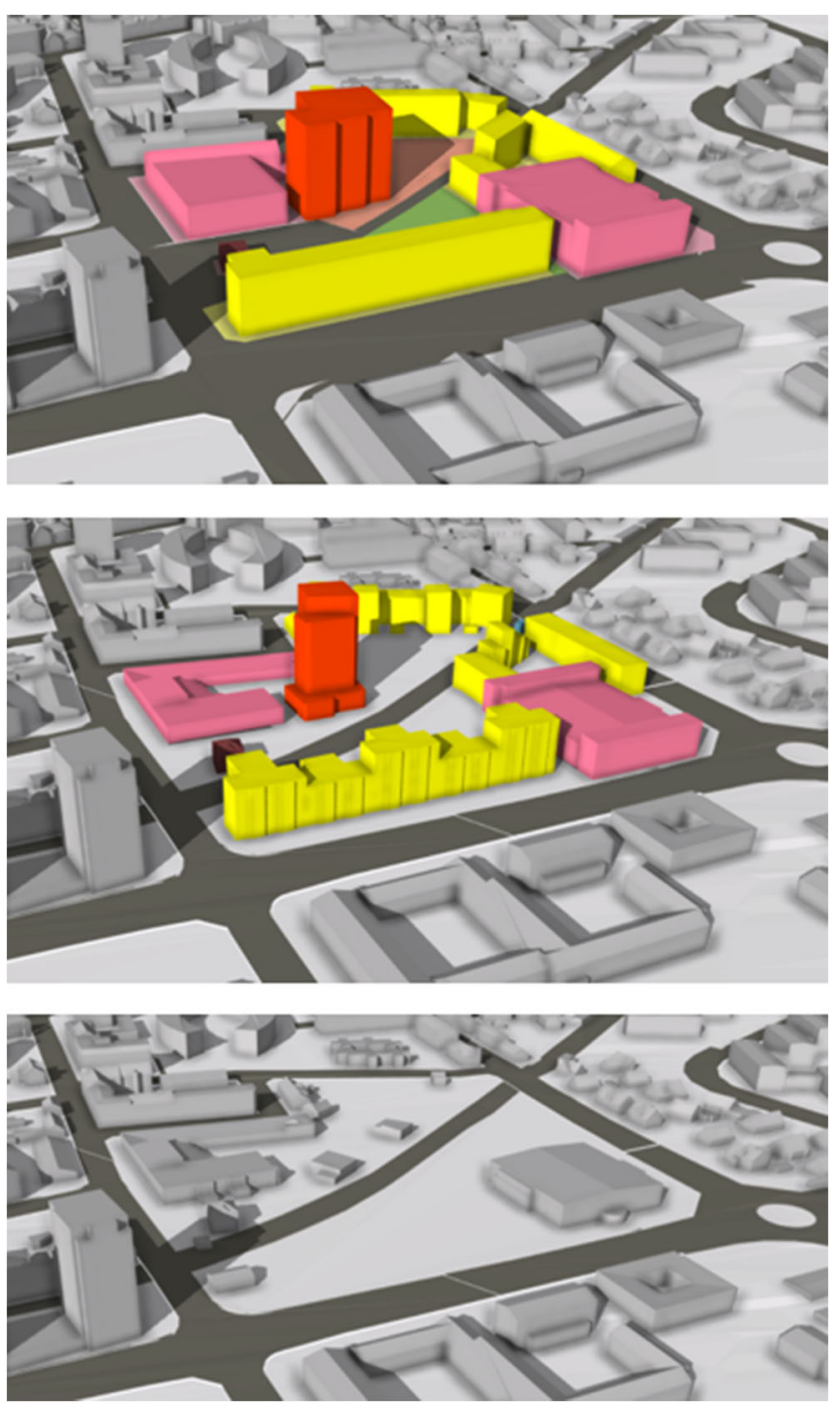

Fig. 11 The three scenarios used during the study are visualized here, using design 1 . The first scenario shows the DDP visualized as the outer envelope of the buildings based on maximum height (top); the second scenario is one possible realization of the buildings (middle); and the third scenario shows existing buildings within the study area (bottom)

\section{Interviews}

Experts were chosen to partake in the study based on having a professional familiarity with the topic, with an attempt made to contact professionals across a variety of associations (Boverket and municipal governments) and locations (Malmo, Lund and Helsingborg) who work with various stages of urban planning (architecture, GIS, building permits). A limited time frame during the study is reflected in the small sample size. Ten people were contacted for interviews, of which two declined, four did not respond, and four agreed, for a $40 \%$ response rate. The makeup of the participant group was half female and half male, with ages ranging from approximately 30 s to 50 s. Participants were sent the questions, the original DDP, and a link to the 3D maps found in ArcGIS Online (Judge 2019) prior to their scheduled interview. During the semi-structured interview process, each participant was asked the same set of open-ended questions (Appendix). The interviews took place at the municipality office in Lund. To ensure the validity of the primary data collection and analysis for the study, the interviews were recorded using an Olympus Digital Voice Recorder (VIN-741PC) with each participant's permission. A summary of the participants' details is found in Table 2.

\section{Qualitative Analysis}

A process of data reduction was completed for each interview with the aim to focus, simplify, and abstract the content of the interview. The interviews were first transcribed; then, the responses were summarized for each question, and finally, key points were highlighted. An important aspect of validity is the ability of the research to demonstrate its statements (Ghauri and Grønhaug 2002); therefore, subsequent interview transcriptions and key points were validated with the participants (i.e., each participant was given an opportunity to confirm their responses in a post-interview). Based on the information summarized from the interviews, the map guidelines were updated, and a final design was created to reflect the results.
Table 2 A summary of the interview participants and details from the study

\begin{tabular}{lllll}
\hline Profession & Job location & Experience & Interview date & Interview duration (min) \\
\hline Plan architect & Urban planning & 8 years & April 17, 2019 & 60 \\
& Helsingborg & & & \\
City engineer & GIS, cadastral services & 16 years & April 18, 2019 & 50 \\
& Lund & & \\
Plan architect & $\begin{array}{l}\text { Urban planning } \\
\text { Lund }\end{array}$ & 3 years & April 24, 2019 & 105 \\
Urban planning intern & $\begin{array}{l}\text { Urban planning } \\
\text { Lund }\end{array}$ & 6 months & & \\
& & & & \\
\end{tabular}


Table 3 The final map guidelines based on qualitative analysis of the 3D DDP designs are presented as cartography or functionality. Items prefaced with $[\mathrm{F}]$ indicate functionality. The column marked "Used" indicates whether the final design (Fig. 12) implements these guidelines. An " $\mathrm{X}$ " indicates full implementation, a "/" indicates partial implementation, and a "." indicates no implementation

\section{Cartography}

\section{Guidelines}

Retain colors from 2D DDP

Retain ground patterns from 2D DDP (i.e., dots or exes)

Include the boundaries of the detailed plan

Include the boundaries of public/private space

Use transparency for the 3D volumes

Include the 2D DDP as an optional base map

Visualize the DDP within a 3D city model

Visualize the default city model in a simple form (light gray, no extra details or facades)

Visualize existing/current study area environment

Visualize at least 2 example designs for the study area visualizations: either plain white, or "gaming-style" iconography

Visualize the default background map in simple form with some environmental details; avoid orthophotos

Visualize the default view without vegetation, but include it as an option

Do not allow vegetation in the 3D DDP unless the regulations include it

Functionality

Guidelines

Retain all the information found in the 2D DDP in the form of an easily searchable legend

\section{buildings}

Give the user options: collapsible menus with options for vegetation, city model, example designs, and background; separate menus for legal regulations and the others

Avoid overwhelming the user with options by utilizing interaction design

Include a help section with explanations of functionality

Include pop-ups with relevant information for each object in the 3D DDP

Include a timeline of the planning process, and an explanation of the level of public participation
Reasoning

- Recognition for planners and citizens

- Visual cue indicating the volumes do not represent buildings (avoids highly realistic representations)

- Visual representation of the plan (main usage)

- Visual representation of the plan (building limitations) $\quad \mathrm{X}$

- Keep the focus on the DDP

- Provide a clear differentiation between DDP and surrounding area

- Indicates where citizens' comments have clout

- Visual cue indicating the volumes do not represent buildings $\mathrm{X}$

- Resulting lighter colors removes the "heavy block" feeling

- Ease the transition from 2D to 3D

- Provides diversity in the ways of disclosing information

- Provides contextual information

- Allows citizens to view the proposal from their property

- Keep focus on the study area

- [F] Allow the user to change the level of detail of the city model

- Provides a reference point for citizens

$\mathrm{X}$

- Match the style to the city model

- Communicates the difference between the DDP and actual / buildings

- Communicates an ongoing planning process

- Communicates the difference between illustrations and reality

- White building models have traditional significance in planning

- Gaming-style iconography provides attractive illustration while avoiding highly realistic representations

- [F] Allow the user to change the visualization

- Keeps focus on the study area

- Provides environmental context for orientation

- [F] Allow the user to change the map

- Reduces the loading time of the application

- Provides environmental context for the viewer

- Lessens the shock of 3D volumes

- [F] Allow the user to toggle vegetation on/off

- Avoid misleading the public

Reasoning

- Allow for 2-way navigation between the model and the information within it

- Communicates the difference between the legal regulations $\mathrm{X}$ and a potential building; indicates uncertainty

- Utilize the flexibility and interactivity of a digital model

- Give the user control over the visualization

- Provides options while maintaining a clear interface to appeal to users of all technologic proficiencies

- Highlights the relevant tools and functions

- Ensure the application and visualization are inclusive to users of all technologic proficiencies

- Provides easy to navigate and clear information for each object

- Highlights the main usage of each area (i.e., sports)

- Communicates the proposal stage and whether the commenting period is still open

- Allows for a transparent comment period

- Shows the progression of the proposal through time 


\section{Results}

The result from the interviews concerns the cartographic design, methods to map uncertainty, and issues concerning the public participation. These results were later used to create the final map guidelines, as described in the later "Discussion" section.

\section{Cartographic Design}

During the interviews, the participants were shown each design in turn and asked to critique them with prompting questions asked by the interviewer. The results from those discussions are summarized for each design below. The cartographic critiques from the participants were parsed out to achieve recommendations for use in national guidelines of 3D DDP visualizations (Table 3 ).

Design 1: The traditional colors aid recognitionespecially for planners, but also for citizens who have previously seen detailed plans - and are a strong visual cue for planning, not reality. It was noted that the box model in high contrast colors felt "too strong." Participants wanted a legend for the plan colors, possibly vegetation, and for the roads within and outside of the study area to be differentiated.

Design 2: The inclusion of some environmental detail and a slightly more realistic environment was better for orientation. In the planning profession, a white box model represents buildings which can be confusing when applied to the maximum restrictions of a DDP instead. Since the DDP is all white, there is no obvious visual cue that the box model is showing something other than buildings, and although the limits of the detailed plan are now easily discernable, the plan decisions are no longer visible. Hence, it appears more as an illustration since it does not convey the regulations. Users felt they were missing transparency, more information, and boundaries and that the detailed plan should be in colors representing their usage.

Design 3: The level of detail distracts viewers and takes too long to load, making it an ineffective work tool. There is a lack of focus on the proposal, as attention is drawn away from the plan to the details around it: the orthophoto, fictitious facades, and vegetation. The use of fictitious facades in the city model would be especially distracting for local citizens; unless there is an exact city model, people will be distracted by inconsistencies between reality and the model. This design does not show the plan details visually, but the boundary of the detailed plan is clearly visible. The vegetation inclusion is good in general as it lessens the shock of big buildings, but trees should not be included in the detailed plan unless it is regulated. One participant thought the trees should be more symbolic.

Design 4: The vegetation provoked much discussion. Among the participants, it was noted both that the symbolic vegetation was better than design 3 and that the symbolic trees were annoying, unnatural, and distracting. It was suggested that the gaming industry had better examples of vegetation to use. The other main comment was the use of different colors for walls and roofs in the study area, which gave the incorrect impression of actual buildings instead of maximum exploitations. The study area appeared like an illustration, while the city model seemed like the planned area due to the association of white 3D models with planning.

\section{Method to Map Uncertainty}

The comparison mode, or slider tool, was demonstrated for the participants during the interview. The reaction from all the participants was positive toward the tool's ability to communicate uncertainty. The participants commented on the modern feel of it and that having multiple scenarios to compare seemed like a good solution to help people understand that they are looking at a proposal. It was deemed effective by all participants, with one interviewee highlighting that the slider was a key part of the design for them. One suggestion was that the slider should always be visible when the user interacts with the model, in other words, that it starts on the screen when the 3D visualization is opened, rather than being an option to turn on or off.

\section{Public Participation}

The evaluation of the potential change in public participation when using $3 \mathrm{D}$ visualizations was also broached in the interviews, and aspects of these conversations were included in the guidelines. The general results are summarized below, while the implications are further discussed in the next section.

\section{Communication Change and Foreseeable Issues with 3D Visualizations}

All the interview participants reiterated that the design of the current 2D DDP is difficult for non-professionals to understand, hindering communication with the public. It was noted that the paper-based document works well from a legal perspective but is outdated in today's world. The participants thought the addition of 3D 


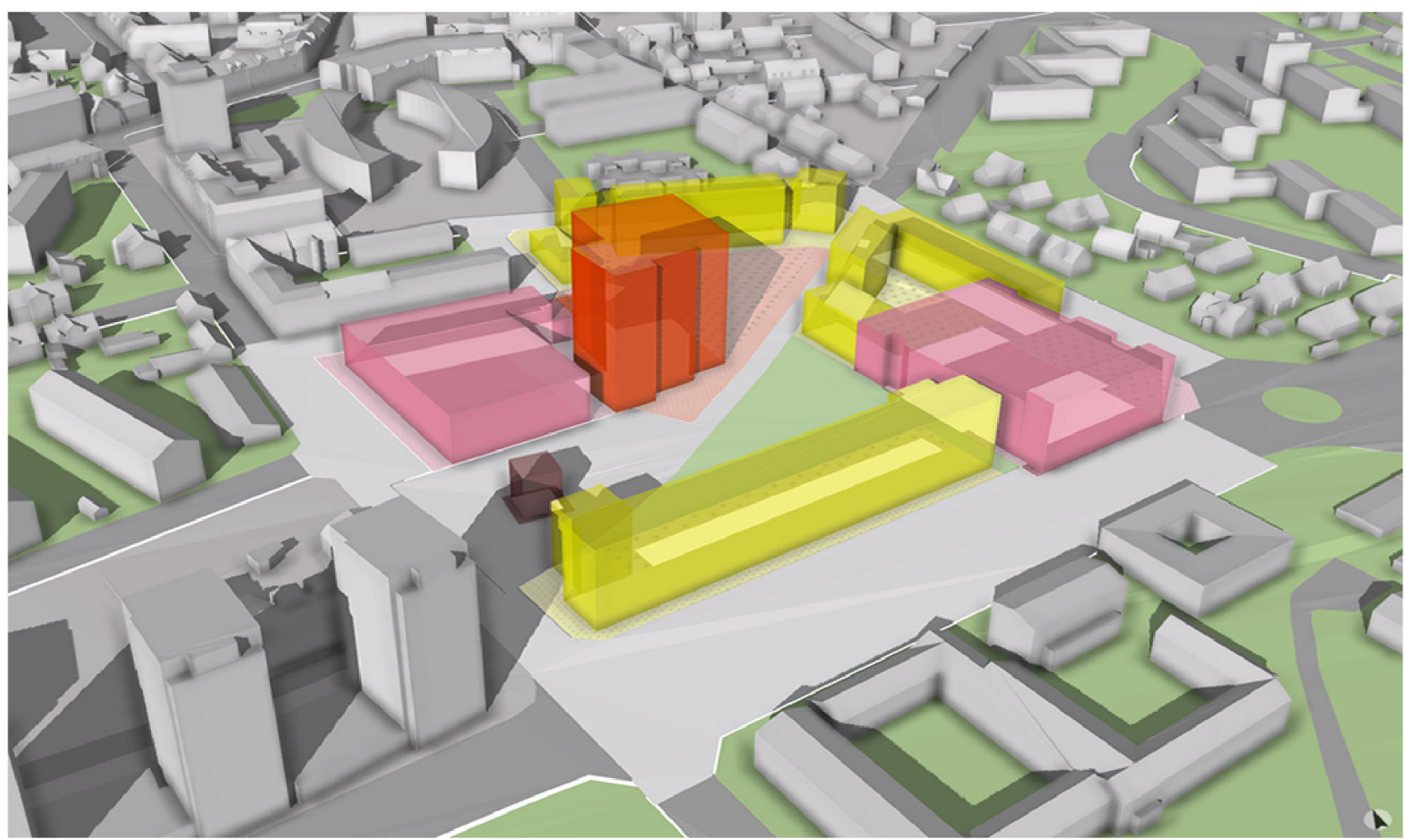

Fig. 12 A final design of the 3D model implementing the map guidelines as given in Table 3

volumes and a dynamic model would make it easier for people to understand the plan proposal; however, everyone also stressed the risk of false perception of the box models and visualizations. The importance of communicating uncertainty and an open planning stage to the public was stressed here. The usability and inclusion of a new technology was also broached by the participants as a possible barrier to the widespread use of $3 \mathrm{D}$ web-based visualizations. Interaction design should be utilized to increase efficiency of the final product. Participants identified the democratic appeal of using interactive and participatory technology as a benefit. Finally, standardization of the $3 \mathrm{D}$ visualizations was discussed as a way to increase the benefits seen.

\section{The Role of Map Guidelines in Support for 3D DDP}

In continuation of the previous point, the existence of map guidelines as a form of standardization was discussed as providing a better framework for development in both software and legal domains. Achieving good guidelines (i.e., appropriate cartographic design and interaction possibilities to reflect the invisible and uncertain elements of the DDP) should aid the user, and having consistency based on map guidelines breeds recognition in the public.

\section{Discussion}

\section{Cartographic Design}

All participants agreed that standardization is needed for 3D DDP visualization. Cities need to produce similar products which allow for professionals and developers to more easily work nationally. Visualization standards (i.e., map guidelines) are an important component of that. As one participant noted, the design of any product tells the user how to interact with it, and the same principle should be applied to the detailed plan. It should be recognizable to people, which requires standards. The importance of map guidelines also comes from the need to differentiate between illustrations and detailed plans, and to map uncertainty. Additionally, legally moving to a 3D environment in the future would require visualization standards.

A clearly emerging idea implicit in the interviews was that moving to a digital web-based model requires the redefinition of map guidelines. Just as appropriate cartography needs to be redefined for a specific visualization, the definition of map guidelines needs to include functionality and interaction design for 3D digital space. This was immediately apparent when the first design critiques in all the interviews were regarding the box model and web viewer, instead of the specific cartography of the study area and background map. This also highlights limitations of existing software and web applications for achieving all the desired functionality for a 3D DDP 
Fig. 13 The use of the comparison mode in the final design is shown here, with the $3 \mathrm{D}$ DDP visualized on the left, and an example illustration on the right

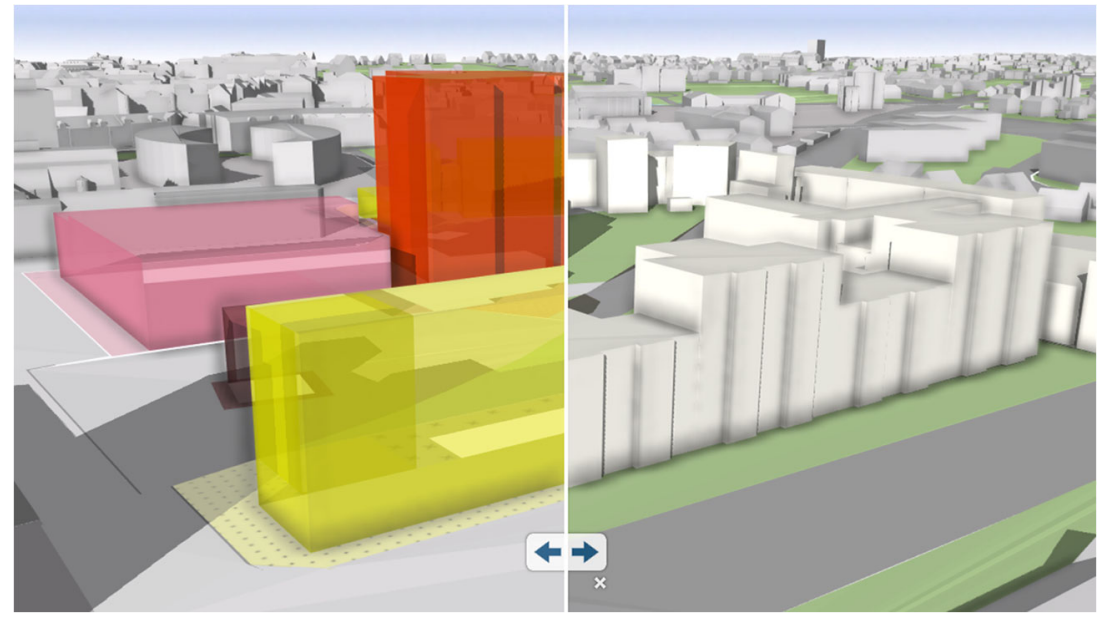

visualization. One participant commented that standardization was more important for software development than for visualization-however, it seems the two are inextricably linked when dealing with 3D digital space. For instance, the desire to have object information in a pop-up rather than in an information pane is dictated by technical tools, e.g., in our study how the 3D model is exported from CityEngine and visualized online (using either CityEngine Web Viewer or ArcGIS Scene Viewer). The adoption of map guidelines could thus result in software or applications tailored to the requirements of a country's planning process.

Comments from the participants also indicate that it could be relevant to look to the gaming industry for better 3D visualizations in some cases (i.e., for vegetation). Previous research conducted on applying gaming design principles to a visualization tool with a scientific purpose found that it may improve the design on the user-end; however, the authors highlight the different goals between gaming and utility software. Further results in the study suggest users push it toward a more playful game-like environment, which may even run contrary to the needs of the software (Fitz-Walter et al. 2016). One challenge in designing the 3D DDP is the need to not mislead the user in what they are viewing. Although 3D visualization from the gaming world may be more esthetically pleasing, it may also run contrary to the goal of communicating uncertainty. This further highlights the need for specific design principles for specific applications.

The participants' views were used to redefine the preliminary guidelines. Design 1 was preferred by every participant due to the recognition of the colors used and the visual representation of the plan proposal (specifically, the proposed use). It was discussed that the use of planning colors also offers a visual cue that the volumes do not represent actual buildings. An oft-heard comment was the need to clearly communicate what the detailed plan shows, especially when it is visualized as a box model. This can be done explicitly, through a text box that explains to the user what they will see, and implicitly, through visual cues like unconventional building colors and transparency.

While most of the preliminary guidelines remained relevant throughout the process, two of the points required change:

- Avoid known visual conflicts in 3D space - in particular, use transparency, shading, and shadow with caution (Neuville et al. 2018)

- Transparency was a key element the participants felt was missing from the $3 \mathrm{D}$ maps. It is a clear visual cue signifying a difference between a maximum exploitation volume and a real building. It should be stressed that this applies to the dynamic model, not a static image of a $3 \mathrm{D}$ model.

- In the web application used to visualize the 3D DDP, shadows are optional and dynamic according to the user.

- Avoid or minimize textual annotations (Camba et al. 2014; Ljungblom et al. 2017)

- It was noted that the 3D models felt too simple at times. More information was desired through pop-ups, or headlines signifying more clearly what the 3D map was showing. Visual clutter should still be avoided, but interaction design should be employed to make the most of textual annotations.

The final map guidelines are outlined in Table 3, found at the end of the "Discussion," and separated into cartography and functionality sections. A design of the new 3D DDP visualization was created that considered as much as possible of the guidelines (Figs. 12 and 13) and can be viewed online (see Judge 2019). 


\section{Method to Map Uncertainty}

The method chosen to map uncertainty in this case study was the comparison mode, or slider tool, which allows a user to choose two scenarios to view side-by-side. This was highlighted by each of the participants as an elegant and simple solution to mapping uncertainty, and a tool that should be carried forward to future 3D DDP visualizations. As noted in previous subsections, other cartographic elements were also chosen to contribute to that goal: namely transparency of the DDP visualization and the use of the "unusual" planning colors to indicate the maximum envelopes were not representing actual buildings. While Neuville et al. (2018) indicated that the use of such intrinsic methods as color and transparency could lead to difficulties in interpretation in 3D space, the participants in this case study were in agreement that these elements be included. As such, the final method for mapping uncertainty was a combination of the extrinsic approach of the comparison mode and the intrinsic approach of color and transparency.

\section{Public Participation}

Public participation was discussed with the participants in the context of the planning process (in Sweden). One theme raised during these discussions was regarding democracy and a wellfunctioning society, in that urban planning affects the public's everyday lives, so the public must understand plan proposals and have the ability to comment on it. Participants said the 3D model is easier to understand for everyone involved in the process, and it is more democratic to use a model that is easier to understand. One participant commented that the interactivity of digital media supports a participatory culture and establishes a strong connection between laypeople and the designers. The importance of social inclusion in sustainable development has been previously established by the United Nations (United Nations 2016b); although two participants highlighted that while public participation is important for social development, it does not necessarily directly benefit the economic and ecological aspects of sustainable development.

The second theme was regarding the tangible benefit to the plan design. Participants noted public participation helps planners understand aspects that might otherwise be missed, as generally, more people thinking about a plan leads to a better result. Boverket has also recognized the benefit of including local knowledge in plan proposals (Boverket 2018).

The general comments about the current design of the 2D DDP included the difficulty in understanding the plan proposal due to the overwhelming amount of information shown on it, coupled with the need for previous knowledge to translate the symbols and markings. The information density of the design hampers viewers in imagining the outcome of the plan, and the inclusion of an illustration may pull focus away from the plan proposal. The paper-based DDP was called oldfashioned and a "dead document" but was noted by one participant to work well from the legal aspect.

In contrast, each participant indicated that $3 \mathrm{D}$ visualizations are easier for people to understand, a notion supported by myriad previous studies (Kibria et al. 2009; Han et al. 2015; Almqvist et al. 2016; Ljungblom et al. 2017; Onyimbi et al. 2018). The main benefits expressed by the participants and supported by Herbert and Chen (2015) were owing to the dynamism of the model: users can choose their own viewing angles and perspectives, can go to ground level to understand the impact of building heights, and can view the plan from their own property. In short, the 3D digital model provides better opportunities for the public to visualize the real impacts of the proposal and communicates the aim of the plan proposal better.

Several potential risks in moving to 3D models were identified during the interviews. Every participant mentioned the risk of false perception in what the box model represents and highlighted the importance of communicating the difference between what a DDP shows and how it might manifest. Highly detailed renders were identified as increasing this false perception, which is supported in the literature (Smallman and St. John 2005; Kibria et al. 2009; Billger et al. 2016). The challenge of trying to capture everything a detailed plan should communicate is difficult for one model or image, which one participant pointed out is ostensibly one of the reasons it does not exist yet. Although it is difficult to communicate that many variations are possible in the final design, to map uncertainty, it was noted that a $3 \mathrm{D}$ digital model is better suited for the task. It was also noted that the stronger image of a 3D model may elicit stronger reactions (which may require a longer dialogue process), and it can be overwhelming for people to view buildings in $3 \mathrm{D}$ if they are not used to it. This supports the idea of diversity in the ways of disclosing information (Liu et al. 2018), as some people may prefer 2D maps.

The usability or inclusion of a new technology such as a web-based 3D DDP was also discussed. It was noted that there exists a digital gap within a population, as people may have unequal access to computers or Internet, and the public may experience frustration at needing to learn how to navigate a web-based 3D model. One participant had indicated unfamiliarity with the tools and functions available through CityEngine Web Viewer and expressed a desire for a clear introduction upon entering the web scene, while the need for appropriate interaction design was raised several times by another participant. Literature supports the idea that improving the technology alone is not necessarily enough to improve public participation (Senbel and Church 2011; Heiden 2018). As noted by Heiden (2018, p. 9), "technology is neutral, but if a technology is dropped on top of a social structure 
that is unequal, all it will do is exacerbate those inequalities." In this case, the move toward 3D digital models could exclude tech-illiterate citizens, and citizens unable to access the models online. A possible solution is for the city to provide a public-use computer in the municipality building for citizens to access and be shown the 3D models.

\section{Final Map Guidelines}

The final map guidelines are outlined in Table 3 and separated into cartography and functionality sections. Design of new 3 DDP visualization was created that considered as large part as possible of the guidelines (Figs. 12 and 13) and can be viewed online (see Judge 2019).

\section{Study Limitations and Biases}

The difficulty of analyzing free text such as interviews is acknowledged by Ghauri and Grønhaug (2002), who specifically discuss how the interviewer's background may greatly influence the interpretations, thereby causing problems of objectivity. In this case, the key points that were reduced from each interview were sent to the participants as a validation step to remove this bias. The interviewer's bias may also be present in the formulation of the interview questions, although an attempt was made to use neutral language.

Ghauri and Grønhaug (2002) also discuss the bias that relates to over- or underrepresentation of groups within the respondents. This is an admitted bias of this study, which only interviewed participants from the planning point of view, and therefore did not consider the views of third-party architects and laypeople. The preference of all the participants for design 1 , which mimics the current industry standard, may be an indication of this bias, as people tend to prefer the familiar (Zajonc 1968). Further, there is an inherent selection bias, wherein participants who were interested in the subject matter of 3D DDP were quick to agree to participate, whereas disinterested parties who could have provided alternate opinions did not wish to participate. These biases could be alleviated given a longer time frame for the study and the possibility of a larger variety in participants' backgrounds and opinions.

A further limitation of the study comes from the number of interviewees, which included four professionals. The smaller number of participants was accounted for by employing openended interviews rather than questionnaires to encourage deeper discussion. It should also be noted that two participants were interviewed together due to schedule accommodations and work relationships, which may have affected how the individuals answered the questions. However, each participant was still given an opportunity to answer each question individually. Employing a limited number of expert interviews in analyzing 3D visualizations was a method identified in several published studies, either as the sole qualitative analysis (Häberling et al. 2008; Herbert and
Chen 2015), or as a supplement to questionnaires from nonexperts (Nielsen 2005; Schroth et al. 2014; Rautenbach et al. 2016).

\section{Conclusions}

The aim of this study was to improve the DDP visualizations to enhance public participation of the urban planning process. This was divided into the development of cartographic guidelines, the evaluation of a methodology to mapping uncertainty in the DDP, and the discussion of the benefit of interactive web-based 3D DDP visualizations in public participation. The results of the case study are based on semi-structured interviews conducted with four professionals in the fields of urban planning and GIS. The interview participants indicated that a 3D DDP would improve communication of the plan proposal to the public when care is taken to avoid misleading visualizations. It was discussed that the proposal impact is communicated more clearly with a 3D visualization, and that a digital and dynamic model allows more autonomy and flexibility for the user. However, the visualization of maximum volume must be clearly explained and differentiated from the visualization of a potential building. Interaction design needs to be considered for the final application, as there needs to be a balance struck between allowing variety for the user and keeping the overall application simple and intuitive.

The question of whether 3D visualizations improve public participation is more complex. The results from the interviews indicated that map guidelines would create a future where the 3D DDP is recognizable and understood more easily by the people who need to comment on it. However, the literature indicates that improvement in plan communication should not be conflated with an improvement in public participation. While interview participants recognized the importance of public participation for social sustainability, they also raised the question of when public participation occurs to be most impactful, and it was indicated in the literature that true social inclusion and citizen empowerment require more than just a new visualization.

Based on the participants' responses, it was clear that the visualization of a web-based 3D model is inherently tied to the technology behind it. Themes that emerged from the interviews could be broadly grouped as cartography or functionality of the digital application. It was unanimous to keep the traditional planning colors for the detailed plan and to use an element of transparency as a visual cue that the box models do not represent actual buildings. It was also unanimous that a comparison mode provided an appropriate way to communicate uncertainty, the difference between the detailed plan and example designs. It was thought that the flexibility of a digital model should be fully utilized in allowing users to choose backgrounds and city model environments to their likingwith the caveat that an element of interaction design be 
implemented so as not to overwhelm users with options. The detailed map guidelines established as a result of the interviews are included in full in Table 3.

The importance of the planning phase and the role of public participation therein have been well-established in the literature. 3D visualizations have been shown to improve communication with laypeople, which is one part of improving public participation. Sweden is currently focused on improving aspects of its building industry through standardization and new technologies, placing the development of 3D visualizations of DDPs in a particularly relevant spot. The map guidelines established in this study therefore provide a solid foundation for this continued advancement of 3D DDP in Sweden.

However, whether the movement from static $2 \mathrm{D}$ to interactive 3D DDP visualizations will improve public participation in the planning process is a complex issue including aspects of the public's willingness to adapt new technologies. What we can conclude from this study is that several planners think that $3 \mathrm{D}$ visualization will increase the public participation. But to verify this in practice, it would be necessary to interview a much larger, as well as more diverse, group of persons including non-specialists, or to conduct a real-world test where a 3D DDP visualization is created for a real case and also perform a user evaluation based on this visualization.

Acknowledgments Thanks are due to Lund Municipality for providing data and valuable input to this study. We are grateful to our participants, Jonas Andreasson, John Hellman, Ulrika Thulin, and Antoniya Triguerios. Thanks are also due to Safe Software for a free academic license of FME.

Funding Information Open access funding provided by Lund University. This research was funded by the research platform Smart Built Environment, grant number 2016-01981 (financed by Formas, Vinnova, and Swedish Energy Agency), and Lund University.

\section{Compliance with Ethical Standards}

The research conducted for this paper has been in full compliance with ethical standards at Lund University.

Conflict of Interest The authors declare that they have no conflict of interest.

Ethical Approval This study follows the ethical rules at Lund University.

Informed Consent All the participants in the study have seen the result and agreed to be mentioned by name in the paper.

\section{Appendix. Interview questions}

Interviewee Information

- Name

- Job title/department
- Length of time in this profession

- Role in the planning process

- What is your familiarity with the current DDP (i.e. what they normally look like and information they contain)?

RQ1: Does a 3D visualization of a DDP improve communication of the plan proposal to the public?

- What do you think about the design of the current 2D DDP to communicate the plan proposal to the public? (i.e. the cartography and how public participation is affected)

- How would 3D visualizations change communication of the plan proposal to the public?

- Do you foresee issues with using 3D visualizations as a communication tool with the public?

- What role do you think public participation plays in sustainable development?

RQ2: Does the establishment of map guidelines support the use of 3D visualization of DDPs for future public participation? (Disregarding legal aspects.)

- What are the barriers to the use of 3D DDP for public participation?

- What would support the use of 3D DDP?

- Would the establishment of map guidelines for this specific application support the use of 3D DDP? (i.e. instead of making arbitrary design choices, one can consult established guidelines)

RQ3: What are the preferred map guidelines for 3D visualizations of DDPs in Sweden?

For each 3D design:

- What is your initial impression of the design?

- Do you "understand" it immediately?

- Does it communicate the plan proposal effectively?

- Do you see advantages or disadvantages to it?

- Is there anything you would change? Keep?

- What should the final design look like?

Any remaining thoughts/comments/questions/concerns?

Open Access This article is licensed under a Creative Commons Attribution 4.0 International License, which permits use, sharing, adaptation, distribution and reproduction in any medium or format, as long as you give appropriate credit to the original author(s) and the source, provide a link to the Creative Commons licence, and indicate if changes were made. The images or other third party material in this article are included in the article's Creative Commons licence, unless indicated otherwise in a credit line to the material. If material is not included in the article's Creative Commons licence and your intended use is not permitted by statutory regulation or exceeds the permitted use, you will need to obtain 
permission directly from the copyright holder. To view a copy of this licence, visit http://creativecommons.org/licenses/by/4.0/.

\section{References}

Alatalo T, Pouke M, Koskela T, Hurskainen T, Florea C, Ojala T Two real-world case studies on $3 \mathrm{D}$ web applications for participatory urban planning. In: Adcock M, Bednarz T (eds) Proceedings of the 22nd International Conference on 3D Web Technology, Brisbane, Queensland, Australia, 5-7 June 2017 2017. p 9. doi: https://doi.org/10.1145/3055624.3075950

Almqvist A, Lithén T, Ekelund F, Sjölund L (2016) Strategy for 3D spatial data - pre-study report. Stockholm

Arnstein SR (1969) A ladder of citizen participation. J Am Inst Plan 35: 216-224. https://doi.org/10.1080/01944366908977225

Baig SU, Abdul-Rahman A (2013) Generalization of buildings within the framework of CityGML. Geospatial Information Science 16:247255

Bevis Y, Schaab G, Rautenbach V, Coetzee S (2017) Expert opinions on using the third dimension to visualise wind speed uncertainty in wind farm planning. Int J Cartogr 3:61-75. https://doi.org/10. 1080/23729333.2017.1301349

Biljecki F, Stoter J, Ledoux H, Zlatanova S, Çöltekin A (2015) Applications of $3 \mathrm{D}$ city models: state of the art review. ISPRS Int J Geo Inf 4:2842-2889. https://doi.org/10.3390/ijgi4042842

Billger M, Thuvander L, Wästberg BS (2016) In search of visualization challenges: the development and implementation of visualization tools for supporting dialogue in urban planning processes. Environ Plann B 44:1012-1035. https://doi.org/10.1177/ 0265813516657341

Borrmann A, König M, Koch C, Beetz J (Eds) (2018) Building information modeling: technology foundations and industry practice. Springer International Publishing, Cham

Boverket (2018) Citizen dialogue. Boverket. https://www.boverket.se/sv/ samhallsplanering/sa-planeras-sverige/kommunal-planering/ medborgardialog 1/. Accessed 6 February 2019

Buttenfield BP, Weibel R (1988) Visualizing the quality of cartographic data. Paper presented at the Third International Geographic Information Systems Symposium (GIS/LIS), San Antonio, Texas,

Camba J, Contero M, Johnson M Management of visual clutter in annotated 3D CAD models: a comparative study. In: Marcus A (ed) Design, user experience, and usability: user experience design for diverse interaction platforms and environments, Heraklion, Crete, Greece, 22-27 2014. Lecture Notes in Computer Science. Springer, pp 405-416

Carver S, Evans A, Kingston R, Turton I (2001) Public participation, GIS, and cyberdemocracy: evaluating on-line spatial decision support systems. Environ Plann B 28:907-921. https://doi.org/10.1068/ b2751t

Collinson A (1997) Virtual Worlds. Cartogr J 34:112-124

Combrinck C, Coetzee S, Bevis Y, Rautenbach V (2015) Evaluating procedural modelling for 3D models of informal settlements in urban design activities. S Afr J Sci 111. https://doi.org/10.17159/sajs. 2015/20150100

Davis TJ, Keller CP (1997) Modelling and visualizing multiple spatial uncertainties. Comput Geosci 23:397-408. https://doi.org/10.1016/ S0098-3004(97)00012-5

Djurcilov S, Kim K, Lermusiaux P, Pang A (2002) Visualizing scalar volumetric data with uncertainty. Comput Graph 26:239-248. https://doi.org/10.1016/S0097-8493(02)00055-9

Dübel S, Röhlig M, Tominski C, Schumann H (2017) Visualizing 3D terrain, geo-spatial data, and uncertainty. Informatics 4. https://doi. org/10.3390/informatics4010006
Fan H, Meng L (2012) A three-step approach of simplifying 3D buildings. Int J Geogr Inf Sci 26:1091-1107

Fitz-Walter Z, O'Donoghue SI, Baldi BF, Hogan J, Johnson D, Brereton M (2016) Using videogames to improve molecular graphics tools. Paper presented at the Proceedings of the 28th Australian Conference on Computer-Human Interaction - OzCHI 16,

Ghauri P, Grønhaug K (2002) Research methods in business studies, a practical guide, Second edn. Pearson Education Limited, London

Glander T, Döllner J (2009) Abstract representations for interactive visualization of virtual 3D city models. Comput Environ Urban Syst 33: 375-387. https://doi.org/10.1016/j.compenvurbsys.2009.07.003

Gröger G, Plümer L (2012) CityGML - interoperable semantic 3D city models ISPRS. J Photogr Remote Sens 71:12-33. https://doi.org/10. 1016/j.isprsjprs.2012.04.004

Gröger G, Kolbe TH, Nagel C, Häfele K-H (eds) (2012) OGC 12-019 OpenGIS City Geography Markup Language (CityGML) Encoding Standard

Häberling C, Bär H, Hurni L (2008) Proposed cartographic design principles for 3D maps: a contribution to an extended cartographic theory. Cartographica 43:175-188. https://doi.org/10.3138/carto.43.3. 175

Han SH, Hasan S, Bouferguène A, Al-Hussein M, Kosa J (2015) Utilization of 3D visualization of mobile crane operations for modular construction on-site assembly. J Manag Eng 31. https://doi.org/ 10.1061/(asce)me.1943-5479.0000317

Heiden W (2018) Coopting cops with maps: the rhetorical power of cartography in modern policing. Cartographica 53:62-71. https:// doi.org/10.3138/cart.53.1.2017-0026

Herbert G, Chen X (2015) A comparison of usefulness of 2D and 3D representations of urban planning. Cartogr Geogr Inf Sci 42:22-32. https://doi.org/10.1080/15230406.2014.987694

Jones K, Devillers R, Bédard Y, Schroth O (2013) Visualizing perceived spatial data quality of 3D objects within virtual globes. Int J Digit Earth 7:771-788. https://doi.org/10.1080/17538947.2013.783128

Judge S (2019) 3D DDP Visualization. https://www.arcgis.com/home/ group.html?id=cd1fb0dc80174a4795a634def00bc64b\#overview

Julin A et al (2018) Characterizing 3D city modeling projects: towards a harmonized interoperable system. ISPRS Int J Geo Inf 7. https://doi. org/10.3390/ijgi7020055

Kada M Generalisation of 3D building models by cell decomposition and primitive instancing. . In: Joint ISPRS workshop on visualization and exploration of geospatial data, Stuttgart, Germany, 29-30 June 2007

Kibria MS, Zlatanova S, Itard LCM, Van Dorst MJ (2009) GeoVEs as tools to communicate in urban projects: requirements for functionality and visualization. In: Lee J, Zlatanova S (eds) 3D Geoinformation sciences. Springer, Heidelbeirg pp 379-395. doi: https://doi.org/10.1007/978-3-540-87395-2

Laksono DAT (2019) Utilizing a game engine for interactive 3D topographic data visualization. ISPRS Int J Geo Inf 8. https://doi.org/10. 3390/ijgi8080361

Lantmäteriet (2019) Målbilden för en obruten digital samhällsbyggnadsprocessen 2025. https://www.lantmateriet.se/sv/ Om-Lantmateriet/Samverkan-med-andra/lantmateriet\%2D\%2Dutvecklingsmyndighet-for-samhallsbyggnadsprocessen/ kompetenssatsning/malbilden-for-en-obruten-digitalsamhallsbyggnadsprocessen-2025/?faq $=00$ ac. Accessed May 23 2019

Liu B, Wang X, Xia N, Ni W (2018) Critical success factors for the management of public participation in urban renewal projects: perspectives from governments and the public in China. J Urban Plann Dev 144. https://doi.org/10.1061/(asce)up.1943-5444.0000467

Ljungblom M, Nellerup J, Hellman J, Johansson L, Danielsson S, Andreasson J, Hagberg P (2017) Digital detailed planning process with 3D visualization and analysis: project report group 2 within "Information Supply for Planning, Building and Building Permits" 
MacEachren AM, Robinson A, Hopper S, Gardner S, Murray R, Gahegan M, Hetzler E (2005) Visualizing geospatial information uncertainty: what we know and what we need to know. Cartogr Geogr Inf Sci 32:139-160. https://doi.org/10.1559/ 1523040054738936

Mao B, Harrie L (2016) Methodology for the efficient progressive distribution and visualization of $3 \mathrm{D}$ building objects. ISPRS Int J Geo Inf $5: 418-446$

Mather LW, Robinson P (2016) Civic crafting in urban planning public consultation. Int J E-Planning Res 5:42-58. https://doi.org/10.4018/ ijepr.2016070104

McLaren Loring J (2007) Wind energy planning in England, Wales and Denmark: factors influencing project success. Energy Policy 35: 2648-2660. https://doi.org/10.1016/j.enpol.2006.10.008

Minocha S, Reeves AJ (2010) Interaction design and usability of learning spaces in 3D multi-user virtual worlds. In: D. K, R. O, P. Y, T. C (eds) Human work interaction design: usability in social, cultural and organizational contexts, vol 316. IFIP Advances in Information and Communication Technology. Springer, Heidelberg. doi:https://doi.org/10.1007/978-3-642-11762-6_13

Morton PJ, Horne M, Dalton RC, Thompson EM 2012 Virtual city models: avoidance of obsolescence. In: Digital physicality, Proceedings of the 30 th eCAADe Conference, Prague, Czech Republic, 12-14 September

Muehlenhaus I (2013) The design and composition of persuasive maps. Cartogr Geogr Inf Sci 40:401-414. https://doi.org/10.1080/ 15230406.2013.783450

Neuville R, Pouliot J, Poux F, de Rudder L, Billen R (2018) A formalized $3 \mathrm{D}$ geovisualization illustrated to selectivity purpose of virtual $3 \mathrm{D}$ city model. ISPRS Int J Geo Inf 7. https://doi.org/10.3390/ ijgi7050194

Nielsen A (2005) Visual representations, usability and urban planning in real-time 3D geovisualization. Paper presented at the 8th AGILE Conference, Estoril, May 26-28

Obermeyer NJ (2013) The evolution of public participation GIS. Cartogr Geograph Inform Sys 25:65-66. https://doi.org/10.1559/ 152304098782594599

Onyimbi J, Koeva M, Flacke J (2018) Public participation using 3D webbased city models: opportunities for E-participation in Kisumu, Kenya. ISPRS Int J Geo Inf 7. https://doi.org/10.3390/ijgi7120454

Peters S, Jahnke M, Murphy CE, Meng L, Abdul-Rahman A (2017) Cartographic enrichment of 3D city models - state of the art and research perspectives. In: Abdul-Rahman A (ed) Advances in 3D geoinformation. Lecture Notes in Geoinformation and Cartography. Springer, Cham

Rautenbach V, Coetzee S, Çöltekin A (2016) Investigating the use of 3d geovisualizations for urban design in informal settlement upgrading in South Africa. Int Arch Photogramm Remote Sens Spatial Inf Sci XLI-B2:425-431. https://doi.org/10.5194/isprs-archives-XLI-B2425-2016

Reika S, Weimin G (2011) The use of 3d design tools with game-like functionality and physiological information in urban planning and architectural design. Procedia Environ Sci 10:170-177. https://doi. org/10.1016/j.proenv.2011.09.030

Schroth O, Angel J, Sheppard S, Dulic A (2014) Visual climate change communication: from iconography to locally framed $3 \mathrm{D}$ visualization. Environ Commun 8:413-432. https://doi.org/10. 1080/17524032.2014.906478

Seipel S, Lim NJ (2017) Color map design for visualization in flood risk assessment. Int J Geogr Inf Sci 31:2286-2309. https://doi.org/10. 1080/13658816.2017.1349318

Semmo A, Hildebrandt D, Trapp M, Döllner J (2012, 2012) Concepts for cartography-oriented visualization of virtual 3D city models. Photogramm Remote Sens Geoinform:455-465

Semmo A, Trapp M, Jobst M, J. D (2015) Cartography-oriented design of 3D geospatial information visualization - overview and techniques Cartogr J 52:95-106

Senbel M, Church SP (2011) Design empowerment. J Plan Educ Res 31: 423-437. https://doi.org/10.1177/0739456x11417830

Smallman HS, St. John M (2005) Naive realism: misplaced faith in realistic displays. Ergon Des 13:6-13. https://doi.org/10.1177/ 106480460501300303

Stouffs R, Tauscher H, Biljecki F (2018) Achieving complete and nearlossless conversion from IFC to CityGML. ISPRS Int J Geo Inf 7. https://doi.org/10.3390/ijgi7090355

Sun J, Olsson P, Eriksson H, Harrie L (2019) Evaluating the geometric aspects of integrating BIM data into city models. J Spat Sci:1-21. https://doi.org/10.1080/14498596.2019.1636722

United Nations (2016a) Goal 11: make cities inclusive, safe, resilient and sustainable. United Nations. https://www.un.org/ sustainabledevelopment/cities/. Accessed 6 February 2019

United Nations (2016b) The sustainable development agenda. https:/ www.un.org/sustainabledevelopment/development-agenda/. Accessed 22 March 2019

United Nations The Rio Declaration on Environment and Development. In: Nations U (ed) United Nations Conference on Environment and Development, Rio de Janerio, Brazil, 3-14 June 1992. p 19

Wanarat K, Nuanwan T (2013) Using 3D visualisation to improve public participation in sustainable planning process: experiences through the creation of Koh Mudsum plan. Thailand Procedia Soc Behav Sci 91:679-690. https://doi.org/10.1016/j.sbspro.2013.08.469

Wilkening J, Fabrikant SI (2011) How do decision time and realism affect map-based decision making? Paper presented at the 10 th International Conference, COSIT,

Wroblewski A, Leitner A (2009) Between scientific standards and claims to efficiency: expert interviews in programme evaluation. In: Bogner A, Littig B, Menz W (eds) Interviewing experts. Research Method Series. Palgrave MacMillan, pp 235-251

Yan W, Culp C, Graf R (2011) Integrating BIM and gaming for real-time interactive architectural visualization. Autom Constr 20:446-458. https://doi.org/10.1016/j.autcon.2010.11.013

Zajonc RB (1968) Attitudinal effects of mere exposure. J Pers Soc Psychol 9:1-27. https://doi.org/10.1037/h0025848

Zanola S, Fabrikant S, Coltekin, A (2009) The effect of realism on the confidence in spatial data quality in stereoscopic 3D displays. Proceedings of the 24th International Cartography Conference (ICC 2009), Santiago, Chile 15-21

Publisher's Note Springer Nature remains neutral with regard to jurisdictional claims in published maps and institutional affiliations. 